\title{
GPS Water Vapour Tomography: Preliminary results from the ESCOMPTE Field
}

\section{Experiment}

\section{Champollion, ${ }^{\mathrm{a}, *}$, F. Masson ${ }^{\mathrm{a}}$, M.-N. Bouin ${ }^{\mathrm{b}}$, A. Walpersdorf ${ }^{\mathrm{c}}$, E. Doerflinger ${ }^{\mathrm{a}}$, O. Bock ${ }^{\mathrm{d}}$,}

\section{J. Van Baelen ${ }^{\mathrm{e}}$.}

${ }^{a}$ Lab. Dynamique de la Lithosphère / CNRS, Montpellier, France, ${ }^{b}$ Institut Géographique National, Saint-Mandé, France, ${ }^{\mathrm{c}}$ Lab. Géophysique Interne et Tectonophysique / CNRS, Grenoble, France, ${ }^{\mathrm{d}}$ Service d'Aéronomie / CNRS, Université Paris VI, Paris, France,${ }^{\mathrm{e}}$ CNRM/GAME, MétéoFrance / CNRS, Toulouse, France

\begin{abstract}
Water vapour plays a major role in atmospheric processes but remains difficult to quantify due to its high variability in time and space and the sparse set of available measurements. The GPS has proved its capacity to measure the integrated water vapour at zenith with the same accuracy as other methods. Recent studies show that it is possible to quantify the integrated water vapour in the line of sight of the GPS satellite. These observations can be used to study the 3D heterogeneity of the troposphere using tomographic techniques. We develop three-dimensional, tomographic software to model the three-dimensional distribution of the tropospheric water vapor from GPS data. First the tomographic software is validated by simulations based on the realistic ESCOMPTE GPS network configuration. Without a priori information the absolute value of water vapour is less resolved as opposed to relative horizontal variations. During the ESCOMPTE field experiment, a dense network of 17 dual frequency GPS receivers was operated for two weeks within a $20 \mathrm{~km}$ x $20 \mathrm{~km}$ area around Marseille (Southern France). The network extends from sea level to the top of the Etoile chain ( $700 \mathrm{~m}$ high). Optimal results have been obtained with a time windows of 30min intervals and input data evaluation every $15 \mathrm{~min}$. The optimal grid for the ESCOMTE geometrical configuration has a horizontal step size of $0.05^{\circ}$ by $0.05^{\circ}$, and $500 \mathrm{~m}$ vertical step size. Second we have compared the results of real data inversions with independent observations. Three inversions have been compared to three successive radiosonde launches and shown to be consistent. A good resolution compared to the a priori information is obtained up to heights of $3000 \mathrm{~m}$. A humidity spike at $4000 \mathrm{~m}$ altitude remains unresolved. The reason is probably that the signal is spread homogeneously over the whole network and that such a feature is not resolvable by tomographic techniques. The results of our pure GPS inversion show a correlation with meteorological phenomena. Our measurements could be related to the land/sea breeze. Undoubtedly, tomography has some interesting potential for the water vapor cycle studies at small temporal and spatial scales.
\end{abstract}

Keywords: GPS, Tomography, Water Vapour, ESCOMPTE, Troposphere, Integrated Water Vapour. 
* Corresponding author. Tel.: +33-04-67-14-45-91; fax: +33-04-67-52-39-08

E-mail address: Cedric.Champollion@dstu.univ-montp2.fr (C. Champollion)

\section{Introduction}

Water vapour plays a major role in atmospheric processes but remains difficult to quantify due to its high variability in time and space and the sparse set of available measurements. Therefore, the role of water vapour in precipitation, energy transfer or radiation budget remains poorly described. The GPS has proved its capacity to measure the integrated water vapour at zenith with the same accuracy as other methods (radiosondes (Tregoning et al., 1998), water vapor radiometers (Rocken et al., 1995, Doerflinger et al. 1998)). The GPS has shown to be of great interest in meteorology and in climatology (Bevis et al., 1992, Yuan et al., 1993, Businger et al., 1996; Duan et al., 1996; Fang et al., 1998; Tregoning et al., 1998, Ware et al., 2000, Jerret and Nash, 2001, Gradinarsky et al., 2002) because of its (increasing) spatial density and its continuous recording of the state of the water vapour in the atmosphere. Compared to water vapour radiometers, GPS operates in all weather conditions without need of complicated calibration. The assimilation of GPS measurements in numerical weather prediction models is under investigation in several laboratories (Gutman et al., 2003) and should improve the description of the humidity field and the precipitation forecasts. Recent studies show that it is possible to quantify the integrated water vapour in the line of sight of the GPS satellite (e.g. Ware et al., 1997, Alber et al., 2000, Braun et al., 2003). These observations can be used to study the 3D heterogeneity of the troposphere using tomographic techniques.

Tropospheric tomography consists of the retrieval of a 3D scalar field of the water vapour from integrated measurements. Tomographic techniques have been intensively used in recent decades in medicine to investigate the human body or in seismology to describe the seismic velocity anomaly of the Earth's interior. In these two domains, tomographic inversion is well constrained by a sufficient amount of data which can be accumulated because the structures investigated do not change in time. The tomography of tropospheric water vapour is less well constrained due to the limited number of simultaneously visible GPS satellites and the great temporal variability of the water vapour. The first tropospheric tomography studies of water vapor have been performed by Flores et al. (2000a) and Flores (2000b) on the Kilauea volcano (Hawaii) and by Gradinarsky (2002) in the Göteborg region (Sweden). These experiments have been able to prove the feasibility of GPS tropospheric tomography. However, the data sets are limited by the number of GPS stations or by the lack of other meteorological data. The dedicated network for water vapour tomography was deployed during the ESCOMPTE field experiment conducted in Marseille (South of France) in June and July 2001. A dense GPS network was installed during the extensive campaign of pollution and atmospheric measurements ESCOMPTE (more information available on the website: http://medias.obsmip.fr/escompte). This particular setting provides a good opportunity for the validation of the tomographic solution, for its interpretation and meteorological valorization. 
Considering the dispersive character of the ionosphere for the GPS frequencies, ionospheric effects are minimised using a fitted linear combination of the two GPS frequencies (Brunner and $\mathrm{Gu}$, 1991). Conversely, the tropospheric effects are not frequency dependent below $15 \mathrm{GHz}$. The main effect of the troposphere on GPS positioning is an extra delay of the radio signal emitted by the GPS satellites (Davis et al., 1985). This delay is time varying due to the variable pressure, temperature and water vapour content of the atmosphere and cannot be modelled or predicted with sufficient precision for high precision positioning, especially in near real-time. This delay is nowadays the major error source for precise positioning. To model out the perturbation, a set of tropospheric parameters is estimated during the GPS data analysis: Zenith delays, and more recently, horizontal gradients. The correlation between these delays and the state of the atmosphere makes the GPS an efficient tool for meteorological observation. In this study, we will describe the techniques for the retrieval of Zenith Total Delay (ZTD in the following) and the conversion to Slant Integrated Water Vapour (SIWV in the following) between each GPS receiver and each GPS satellite. The SIWV values are the input data for the tomography. We will discuss the implications of the accuracy of the SIWV signal for the interpretations of the results. We explain the theory of our tomographic inversion and its limitations based on synthetic results. Then we describe the ESCOMPTE field experiment and the GPS data analysis. Finally, we show some preliminary results from the inversion of the ESCOMPTE GPS data and a first tentative of meteorological interpretation.

\section{From the GPS signal to the tomographic modelling}

Atmospheric measurements with GPS are based on the propagation delay of the signal through the real atmosphere with respect to the propagation of the same signal in a vacuum. The tropospheric delay $\Delta L$ is obtained by integrating the neutral refractivity $N(l)$ along the path $L$ between the satellite and the receiver:

$$
\Delta L=\int_{L} 10^{-6} N d l
$$

The path $L$ is calculated from Fermat's law of wave's propagation. The bending of the ray is implicitly included in the mapping function described later. The refractivity can be expressed as a function of the "dry" air pressure $P_{d}$, the temperature $T$ and the water vapour partial pressure $P_{w}$ :

$$
N=k_{1} \frac{P_{d}}{T} Z_{d}^{-1}+k_{2} \frac{P_{w}}{T} Z_{w}^{-1}+k_{3} \frac{P_{w}}{T^{2}} Z_{w}^{-1}
$$

where $Z_{d}^{-1}=1.00027$ is the inverse of the "dry" air compressibility, $Z_{w}^{-1}=1.00201$ the inverse of the water vapour compressibility and $k_{1}=77.60 \pm 0.05 \mathrm{~K} / \mathrm{hPa}, \quad k_{2}=70.4 \pm 2.2 \mathrm{~K} / \mathrm{hPa}$, $k_{3}=(3.739 \pm 0.012) \cdot 10^{5} \mathrm{~K}^{2} / \mathrm{hPa}$ (Bevis et al., 1994).

In the GPS data analysis, the delay is expressed at the zenith in two parts: 


$$
Z T D=Z H D+Z W D
$$

where ZHD and ZWD are the hydrostatic and wet parts of the ZTD.

From equation (3) we can remove the "dry" or hydrostatic delay depending only on the total pressure and the temperature. The zenith hydrostatic delay ZHD is accurately estimated from the surface pressure $P_{0}$ and the variation of the gravity field $f$ with the latitude $\varphi$ and the height above the geoids $H$ in kilometres (Davis et al., 1985):

$$
Z H D=\left[(0.0022768 \pm 0.0000015) m \cdot h P a^{-1}\right] \frac{P_{0}}{f(\varphi, H)}
$$

$$
\text { with } f(\varphi, H)=1-0.00265 \cos (2 \varphi)-0.000285 H
$$

The remaining zenith "wet" delay ZWD is simply the difference between the ZTD and the ZHD. The Zenith Integrated Water Vapour IWV is nearly proportional to the ZWD, with a conversion factor $\Pi$ (in $\mathrm{kg} / \mathrm{m} 3$ ) expressed after Bevis et al. (1992) as:

$$
\Pi=\frac{10^{6} m_{w}}{\left(k_{2}-k_{1} \frac{m_{w}}{m_{d}}+\frac{k_{3}}{T_{m}}\right) R^{*}}
$$

where $T_{m}$ is a so-called "mean temperature", $m_{w}$ the molar mass of water vapour, $m_{d}$ the molar mass of dry air and $R^{*}$ the ideal gas constant. The relation between the ground temperature and the mean temperature $T_{m}$ can be empirically determined from a data set of regional radio-soundings with an accuracy of $2 \%$ (Bevis et al., 1992). But for this study we assume an accuracy of $1 \%$ because we use the data from the three radio-soundings launch within the GPS network at each time of the three tomographic inversions presented and we integrate numerically the formula:

$$
T_{m}=\int \frac{P_{w}}{T} d z / \int \frac{P_{w}}{T^{2}} d z
$$

Finally, we have:

$$
I W V=\Pi \times Z W D
$$

The integrated water vapour in the vertical column is retrieved from slant wet delays to all the satellites observed by a ground-based GPS station. The cone on Figure 1 is limited by the minimum elevation of the GPS observations. Comparisons with radio-soundings, Very Long Baseline Interferometry and radiometer measurements lead to an accuracy of about $0.8 \mathrm{~kg} / \mathrm{m}^{2}$ for GPS derived IWV (Foelsche and Kirchengast, 2001; Niell et al., 2001).

\section{From zenith delay to slant integrated water vapour content}

The zenithal delays are mapped to the zenith to form the slant delays observed between the GPS satellites and antennas with $m_{h}$ and $m_{w}$ the corresponding "dry" and "wet" mapping functions. In this study we use the Niell hydrostatic and wet mapping functions (Niell, 1996). Any atmospheric behaviour departing from this assumed azimuthal symmetry (e.g. lateral heterogeneity) cannot be 
reproduced by this horizontal layer model (Bock et al., 2001). We can improve the model by estimating gradients in the North-South and East-West direction. The gradients (Figure 1) are fit to minimise the non-modelled residuals as described by Davis and al. (1993) and Chen and Herring (1997) and they are expressed in mm of delay at $10^{\circ}$ of elevation. We use this gradients approach in order to introduce troposheric heterogeneity in the GPS solution. The gradients in the hydrostatic component can be calculated (and then removed) from surface measurements. The Slant Integrated Water Vapour (SIWV) are reconstructed from ZWD and gradients, they are the input data (or observations) for our tomographic inversion. Namely, the SIWV is now expressed as:

$$
\frac{S I W V}{\Pi}=m_{w}(e) Z W D+m_{\Delta}(e) \cot (e)\left[G_{N} \cos \phi+G_{E} \sin \phi\right]
$$

with the above notations, $e$ the elevation angle, $G_{N}, G_{E}$ and $m_{\Delta}$ being the N-S gradient of ZTD, the E-W gradient of ZTD and the gradient mapping function respectively (Chen and Herring, 1997). All the atmospheric variability cannot be completely described by such a model, the post fit residuals can be added to the Slant Wet Delays. The post fit residuals are the difference between the phase observations and the signal reconstruction at each epoch between each satellite-station pair, including the clock's error, the multipath, the phase centre variations and the atmospheric unmodelled effects. These components are not easily removed, even with the stacking method used by Braun (2001). Quantifying exactly the real part of the atmospheric non modelled effects in these residuals is not feasible yet.

As the gradients are an average over all the visible satellites, the noise level is still lower than the post fit residuals. During the ESCOMPTE campaign, the magnitude of signal level in gradients is typically of about $2 \mathrm{~mm}$ at the zenith, with a RMS of about $0.5 \mathrm{~mm}$. The noise level in the slant delay post fit residuals is equivalent compare to the signal level in the gradients. In this study, we do not use the residuals to avoid contamination from non-atmospheric GPS errors (such as multipath and clock errors) in our observations.

An alternative method is to use directly the double difference residuals which are free from clock's errors. But the methods to extract information from double difference residuals (Alber et al. ,2000) are still discussed and may cause significant systematic errors (Elòsegui and Davis, 2003).

\section{The tomographic inversion: theory and error covariance formulation}

The tomographic inverse problem consists of retrieving the scalar three-dimensional field of water vapour from the values integrated along the ray path (Figure 2b). Since we consider the geometrical effect of the bending of the ray as negligible for elevation angles higher than $10^{\circ}$ (Elgered, 1992), the problem becomes linear. The formulation in the linear discrete theory of the direct problem expresses the link between the observations (SIWV) $Y$ and the true water vapour density $X$ (expressed in $\mathrm{g} / \mathrm{m} 3)$ through the linear operator $M$ :

$$
Y=M X+\varepsilon
$$


Where $\varepsilon$ is the measurement error vector. The linear operator $M$ is expressed as a matrix whose coefficients represent the length of each ray in each cell ( $\triangle S I W V$ in the figure $2 \mathrm{~b})$. To solve the inverse problem, the matrix M must be inverted. As the problem is locally underdetermined (some cells have no rays within), we have to find the "generalised inverse" $M^{g}$ to obtain the reconstructed field $X_{\text {reco }}$ from the data $Y$ :

$$
X_{\text {reco }}=M^{-g} Y
$$

To minimise the ill-conditioning we can add some constraints using a priori information $\left(X_{a p}\right)$. A good a priori field can be water profiles from radio-soundings or radio occultation (above $2 \mathrm{~km}$ ). As the aim of this study is to determine the ability of the tomographic method to reconstruct the water vapour field from GPS data alone, we choose an a priori profile from a standard atmosphere for midlatitude. The optimal case would be if GPS tomography were reliable in every region in every weather condition, even if no radio-soundings are available. Radio-sounding profiles will be used for the validation of the results. To gain some stability in the lowest layer, we use surface measurements of water vapour to initialise the ground level of the standard atmosphere. We could also add some constraints instead of the a priory model to smooth the density field (Flores et al, 2001a; Flores et al, 2001b) but the level of the constraints is difficult to set and can hardly be evaluated from atmospheric physics.

The Bayesian approach in the framework of discrete inverse theory gives us an explicit manner to incorporate a priori information (Foelsche and Kirchengast, 2001, Rodgers, 2000). With the assumption of a linear forward model and of a Gaussian distribution for the a priori and measurement error, we can express the reconstructed field of water vapour $X_{\text {reco }}$ as:

$$
X_{\text {reco }}=X_{a p}+\left[M^{T} C_{y}^{-1} M+C_{a p}^{-1}\right]^{-1} M^{T} C_{y}^{-1}\left(Y-M X_{a p}\right)
$$

where the matrices $C_{y}$ and $C_{a p}$ are respectively the measurement error covariance and the a priori error covariance.

The a priori covariance $C_{a p}$ is chosen to be quite large except for the lowest layer which is partially adjusted to the ground measurement. At the surface, we use an error of $25 \%$, and vary that error up to $100 \%$ at $5000 \mathrm{~m}$ high, based on radio-sounding data sets in Europe (Gradinarsky, 2002). The correlation between two elements of the a priori model is given by a classic Gaussian law in the horizontal and an exponential law in the vertical. The exponential law reflects the high vertical variability of water vapour. We choose a small vertical and horizontal length of Gaussian correlation equal to $0.1 \mathrm{~km}$ and $0.5 \mathrm{~km}$ to avoid some smoothing effects.

The measurement error covariance $C_{y}$ can be split into three different parts: the discretization $C_{d i s}$, the observation $C_{o b s}$ (ZWD and conversion error to SIWV) and the spatial and temporal variations of the humidity field $C_{v a r}$. The discretization error $C_{d i s}$ (based on direct modelling of real data into different grids) shows a white noise level of $2 \%$ for $0.05^{\circ} \times 0.05^{\circ} \times 500$ meter cells with no bias and no correlation. The ZWD error (typically $6 \mathrm{~mm}$ ) is projected along the ray path with the Niell 
mapping function to obtain $C_{o b s}$ (relative to the noise $\varepsilon$ in Equation 7). The error on the $\Pi$ coefficient is based on the estimation of the temperature $T_{m}$ with an error of $1 \%$. These errors do not account for any possible spatial correlation, among ZWD at different sites, because of the lack of knowledge in this domain (Tregoning et al. ,1998). We assume that the uncorrelated errors dominate the total measurement error as we use a network with baseline longer than $2000 \mathrm{~km}$. Finally, the spatial variation within a cell $C_{v a r}$ and the temporal variation during the time of measurement are determined from the interpolation of IWV map for the whole GPS network.

\section{Parameterization of tomographic inversion based on simulated data}

In order to examine the effective resolution of the method, a set of synthetic tests using various models has been performed. We use the real geometric configuration of the ESCOMPTE experiment. In a first step, we test the number of rays needed to solve the inverse problem. A simple set of data, corresponding to $15 \mathrm{~min}$ of GPS data, is formed by the SIWV between each satellite-station pair computed at one epoch. To increase the number of data, it is possible to inverse together several set of data ( 3 sets of data $=30 \mathrm{~min}, 5$ sets of data $=1 \mathrm{~h}$ ). It is also possible to interpolate the data between two epochs to get one set of data each 30s. This allows a denser spatial coverage of the studied region. The best result is obtained using SIWV each 30 s over one hour, allowing the best coverage of the $3 \mathrm{D}$ model as we use the maximum of data. Unfortunately the inversion of real data is much more complex. First, accurate SIWV are needed, avoiding the use of interpolated data. Second the inversion of 5 sets of data implies a time interval too long with respect to the variability of the water vapour field in the troposphere. To obtain a compromise between the quantity of data and the variability of the water vapour field we select a time interval of $30 \mathrm{~min}$. In a second step we test the size of the grid cells. The optimal horizontal size of the cell is equal to the mean distance between the stations $\left(\sim 0.05^{\circ}\right)$. Vertically, the thickness of the layers has to be defined to allow the rays starting from one station to cross the neighbouring cells. Taking the station at the centre of the cell and a minimum elevation angle of $10^{\circ}$, this implies a minimum thickness of the first layer of about $300 \mathrm{~m}$. To confirm these estimations we have performed 2 inversions taking cell sizes of $0.05^{\circ} \times 0.05^{\circ} \times 500 \mathrm{~m}$ and $0.025^{\circ} \times 0.025^{\circ} \times 200 \mathrm{~m}$ respectively. Clearly the set of data does not allow resolving the second grid: This fine grid is not resolvable due to the small amount of data by cell. Only a greater number of stations decreasing the mean distance between the stations could allow the use of smaller cells. Using the $0.05^{\circ} \times 0.05^{\circ} \times 500 \mathrm{~m}$ grid, only $12 \%$ of the cells are empty of ray crossings.

Hereafter we present five synthetic tests performed using a time interval of $30 \mathrm{~min}$ and a grid of $0.05^{\circ} \times 0.05^{\circ} \times 500 \mathrm{~m}$. We study several simple cases to illustrate the geometrical limitations of the method. All the rays between the satellites and the ground receivers must be in the grid so we add large buffer cells around the GPS network. The synthetic data are constructed from the real position of 
the antennas and the satellites. The water vapour density in the atmosphere is set to zero and the anomalies to one. As we look only at the geometrical limitations of the method, there is no noise added to the synthetic data. As the atmospheric model is completely unrealistic we simply use a null a priori model with no particular constraints for the lowest layer. Further synthetic tests will be done in the future with more realistic models from numerical weather simulations. The results for the 4 tests are summarized below (see Figs. 3a to 3d):

1 - A cross-shaped anomaly between 500 and 1000m: the cross is well retrieved except in its eastern part due to the lack of rays in this cell that includes the Garlaban Mountain. A small amount of smearing is observed in the first layer and leads to an underestimation of the value of the anomaly in the cross. Negative values around the cross are due to the inversion scheme which produces the minimal norm solution. The total contrast in the $750 \mathrm{~m}$ slice is about 1 , as expected. To obtain the absolute values of the humidity field, we need a realistic a priori model.

2 - A cross-shaped anomaly between 3500 and 4000m: Once again the cross is well retrieved, with a small amount of smearing in the layer underneath and negative values around the cross. Our data set is capable to detect and recover structures at high altitude.

3 - An homogeneous layer between 2000 and 2500m: The anomaly is more or less homogeneously distributed throughout the whole model except in the first layer. Synthetic data computed through the model can be explained by infinity of layered models with an integrated vertical anomaly of 1 . As the inversion conducts to the minimum norm model, the solution spreads out the anomaly in all the layers. Only the first layer is correct due to the variation of the altitude of the stations.

4 - A homogeneous layer between 0 and 500m: Due to the variation of the altitude of the stations, the rays from the satellites to the stations do not have the same length within the anomaly. Only an anomalous layer at the bottom of the model can explain the synthetic data. This explains why the estimated field resembles the synthetic field. In the eastern part of the model, the topography and the lack of stations explain the large difference between the estimated and synthetic fields.

To summarize, the tomographic inversion is able to restore local anomalies (i.e. anomalies which do not cover the whole studied domain) whatever the height. On the other hand, an extended anomaly cannot be restored, except if it is located at low altitude, below the highest GPS station. In the estimated fields, we have to take into account the possible existence of vertical smearing and horizontal smoothing of the anomalies. Nevertheless the horizontal contrasts are well retrieved and can be used to detect lateral water vapour anomalies.

\section{The ESCOMPTE field experiment: preliminary tomographic results}

The ESCOMPTE campaign (Cros et al., 2004; http://medias.obs-mip.fr/escompte) took place from June 5 to July 13, 2001 in southern France over the region surrounding Marseille and the Berre 
Lagoon. The primary objective of this campaign was the study of pollution generation, distribution, and dissipation over this urban and industrial area and the influence of the local atmospheric dynamics and land-sea breeze system forced by a sharp coastline, rugged orography, and the influence of two large valleys (the Rhône and the Durance). Given the deployment of a very large array of instruments (including surface meteorological stations, wind profilers, lidars and radiosondes) in order to monitor both the photochemical and atmospheric dynamical processes during the field experiment, it was decided to associate a GPS experiment with this campaign in order to share resources and costs. The GPS experiment's objectives include the determination of the IWV with GPS, the study of the evolution of the IWV in conjunction with the atmospheric dynamics, the study of the GPS retrieved horizontal gradients, and the development of tomography for three-dimensional restitution of the atmospheric humidity field (Bock et al., 2004). During the campaign, a GPS network of 16 stations has been deployed over the urban and northern border of Marseille within a square area of roughly 20 by 20 kilometres (Fig. 4). The geometry of the campaign is well suited for tomographic applications due the good height distribution of the GPS receivers (Fig. 4). To complement the GPS network, a set of additional instruments for the remote sensing of water vapour was deployed. At station VALL, a water vapour radiometer and a solar spectrometer were deployed. At the station called AIRB (Aix-lesMilles airbase), the prototype water vapour Raman lidar of Institut Géographique National was operated. These instruments provide independent IWV measurements for comparison and validation of the GPS solutions.

Processing of the GPS data and preliminary validation of ZTD and gradient parameters are described in Walpersdorf et al., 2004. Using the GAMIT/GLOBK software package (King and Bock, 2000), the processing consists of two successive runs. The first one defines the positions of the GPS stations over 24 hour sessions. The second one, tightly constrained positions determined through Kalman filtering, estimates the tropospheric parameters (for each station one ZTD every 15 min and one gradient every $30 \mathrm{~min}$ ) over the entire observing period. Thus, following the strategy described in the previous section, we reconstruct the SIWV from the ZTD and gradients provided. However, due to a lack of surface pressure field measurements over the area of interest, we assume no lateral variation of the pressure field on the domain. The hydrostatic gradient could not be estimated reliably and was not accounted for. Nonetheless, the associated error can be estimated by the spatial variation of the ZHD between the only two points of surface pressure measurements available. It is less than $1 \mathrm{~mm}$ with a very small temporal variability (less than $0.5 \mathrm{~mm}$ ) and deemed negligible in this case. Further work will be done with numerical model or with faraway ground pressure measurements to quantify exactly the gradient in the hydrostatic component.

To perform the tomographic inversion using the observed data of the ESCOMPTE experiment, the best results compared to the radio sounding measurements were obtained with a grid size identical to the synthetic case studies for the horizontal $\left(0.05^{\circ} \times 0.05^{\circ}\right)$ and with a varying grid size in the vertical 
from $500 \mathrm{~m}$ at the ground (sea level) up to $1000 \mathrm{~m}$ at $10000 \mathrm{~m}$ of altitude. This offers a compromise between resolution and accuracy taking into account the increased correlation between the rays at higher altitudes. To validate our results by comparison with radiosonde profiles, we will use the individual $15 \mathrm{~min}$ retrievals. In that case however, $20 \%$ of the grid cells are not sampled. It appears that a better strategy to provide denser cell sampling would have been to dispose of $5 \mathrm{~min}$ GPS solution interval grouped together during half hour time to represent a single "time" in the inversion process. It is also to be noted that further increase of the time span would render the inversion unstable because of the high time variability of the water vapour distribution, even in the dry meteorological conditions of our study.

We compare results from the day 177 (26 June 2001) at the end of Intensive Observation Period $2 \mathrm{~b}$ with three soundings launched from the station CINQ in the center of our GPS network. The launches took place around 12, 14 and 16 hour UTC and used Vaisala RS80 sondes. It should be noticed that the GPS profiles extracted from the tomography are mean values of the water vapour over fifteen minutes period and over a large volume of air. Radiosonde measurements are instantaneous and punctual but the radiosonde ascent takes about half an hour to reach 10000 meters high. Moreover radiosondes are shifted by the wind. Therefore when comparing radiosonde and GPS retrieved absolute humidity profiles, one has to keep in mind these differences. As the two types of measurements are not equivalent, quantitative comparisons are not possible. Figure 5 shows the comparison between the three radiosonde profiles (black curves on fig. $5 \mathrm{a}, 5 \mathrm{~b}$, and $5 \mathrm{c}$ ), the a priori profile used for initialisation (red curves, identical in all panels), and the profile retrieved from tomographic inversion (green curves). The profile retrieved at 12H UTC is in very good agreement with the radiosounding: it follows well the smooth decrease revealed by the radiosonde, quite different from the a priori profile. However, one could argue that above $3500 \mathrm{~m}$, the retrieved profile is drawn back to the a priori model which is then close to the actual humidity profile. For the following comparisons there is less agreement. Indeed, below $3000 \mathrm{~m}$, the agreement between radiosonde and retrieved profile is degraded, while the "spike" in humidity at about $4000 \mathrm{~m}$ is missed. A possible explanation, as demonstrated earlier, could be that a thin layer of higher humidity has penetrated above the entire domain between the two soundings. In such a case, the inversion will not be able to resolve the "anomaly" but will "dilute" it over the entire altitude range. That would explain the fact that the "spike" at $4000 \mathrm{~m}$ is not reproduced by the inversion and that the retrieved profile below and above presents slightly higher values as the humidity content of the anomaly is distributed at the other levels. This interpretation is supported by the radio sounding measurement at Aix-les-Milles $(20 \mathrm{~km}$ to the North) which indicates the same spike at $4000 \mathrm{~m}$ high.

The final objective of GPS tomographic inversion is the retrieval of the three-dimensional distribution of water vapour over the area of investigation. Such an example is depicted in figure 6 where we show successive hourly vertical planes through the studied volume in the N-S and E-W directions from 12 to 14 hour UTC. As all the cells of these vertical slices are sampled, there are no 
possibilities of a water vapour boundary being artificially produced in an unsampled region. In general, the distribution of water vapour is horizontally layered. In the N-S slices, one can observe the appearance of a moist layer moving southward about 1500 meters above what accounts for the urban region of Marseille. Also, a striking feature in the E-W vertical plane is the accumulation of water vapour within the E-W valley from Marseille to Aubagne. The sea breeze would funnel the water vapour along the valley floor, guided by the complex orography. That entire water vapour dynamics is in good agreement with the wind profiler's data available. The wind profiles show between 12 and 14 hour UTC a SW sea breeze below about 1000m and a SE wind above (Delbarre et al., this issue). Although it is still too early in the study to draw definite conclusions on the dynamics involved, this example demonstrates the capabilities of GPS tomographic inversion. One can study the variations of the humidity distribution in conjunction with the local atmospheric dynamics, such as the land-sea breeze effect versus the large-scale circulation.

\section{Conclusions and perspectives}

Our tomographic software is validated by simulations and comparisons of real data inversions with independent observations.

The simulations based on the realistic ESCOMPTE GPS network configuration have shown optimal performance concerning the ray geometry with a ray sampling assuming on 30 min intervals with SIWV values estimated every $5 \mathrm{~min}$. This corresponds to about 200 SIWV observations and only $12 \%$ of unsampled grid cells. The optimal grid has a horizontal step size of $0.05^{\circ}$ by $0.05^{\circ}$, and $500 \mathrm{~m}$ varying vertical cell size. Only a greater number of stations decreasing the mean distance between the stations could allow the use of smaller cells. Places within the model grid where the simulated perturbation was badly resolved can be related to a lack of stations in the realistic network configuration. It should be noticed that without a priori information the absolute value of water vapour is less resolved as opposed to relative horizontal variations.

The ESCOMPTE GPS campaign provided an important data set for tomographic inversion. SIWV values, the input data for the tomography, have been obtained by projecting ZWD and horizontal gradient values on the lines of sight of the GPS satellites. No residuals have been used so far for more stability of the tomographic solution. The grid used for the real data inversion differs from the simulation grid by a varying vertical step size of 500 to $1000 \mathrm{~m}$ from the surface to $10000 \mathrm{~km}$ altitude. The inversion is based on a single evaluation of the observables over a 15 min time span. Three inversions have been compared to three successive radiosonde launches in IOP $2 \mathrm{~b}$ (26 June, 12, 14 and $16 \mathrm{~h}$ UTC). Good resolution compared to the a priori model is obtained up to heights of 3000 $\mathrm{m}$. A humidity spike at $4000 \mathrm{~m}$ altitude present in the $14 \mathrm{~h}$ and $16 \mathrm{~h}$ radiosonde data remains unresolved. The reason is probably that the signal is spread homogeneously over the whole network. Such a feature is not resolvable by tomographic techniques. 
The temporal aspect of the tomography is not yet implemented in our software. Future work will be done to test Kalman filtering to carry out four dimensional tomography. We will gain some precision in the inversion using the last inversion as the a priori model. The performance could be improved by complementing the GPS measurements with independent water vapour observations (for example by raman lidar). Some work is also still needed on the characterization of the GPS residuals. This could be done by a comparison with high resolution ground-based lidar observations. If the residuals are related to higher order atmospheric structure, they could be included in the inversion and increase the resolution. Also a finer time resolution could be used so that an anomaly cannot cross the entire domain between two successive inversions. In a global point of view, the continuous increase of GPS permanent stations densifying the existing networks and the addition of the future GALILEO satellite system will enhance the capacities of the GPS water vapour tomography.

In the framework of the ESCOMPTE project, the method will be used to study the influence on the pollution event of land-sea breeze circulation in association with Lidar observations (Delbarre et al., this issue) and MesoNH modelling (Bastin et al., 2002). The knowledge of the 3D field of water vapour is therefore essential. The water vapour tomography could also be used in quantitative manner for the validation of high resolution numerical models.

The capacities of GPS water vapour tomography shown in this study point out some future applications in validating numerical model, inferring water vapour structure, characterizing diurnal cycles and maybe anthropogenic influence, influence of the vegetation or of soil evaporation/condensation. In the future, the tomographic software will be applied to GPS projects in the framework of OHM-CV (Observatoire Hydrométéorologique Méditerranéen Cévennes-Vivarais), where dense and regional tomography will be compared. In this context, GPS tomography could help to understand the humidity source for heavy orographic precipitation leading to flash floods observed regularly in south-eastern France. The water vapour GPS tomography should be seen as a new tool for meteorologists.

\section{Acknowledgements}

The authors would like to acknowledge the Institut National des Sciences de l'Univers (INSU) of the Centre National de la Recherche Scientifique (CNRS), through the Programme National de Télédétection Spatiale (PNTS), and the Institut Géographique National (IGN) who supported the GPS field experiment. The ESCOMPTE steering comity and the major French contributors to the ESCOMPTE field campaign (Agence de l'environnement et de la maîtrise de l'énergie - ADEME -, Ministère de l'aménagement du territoire et de l'environnement - MATE -, INSU and Météo-France) are also acknowledged. The authors would also like to acknowledge the people from Marseille who kindly accepted to host a GPS receiver in their gardens or on the roofs of their houses. 


\section{References}

Alber, C., Ware, R., Rocken, C. and Braun, J., Obtaining single path phase delays from GPS double differences, Geophys. Res. Lett., 27, 2661-2664, 2000.

Bastin, S., Drobinski, P., Dabas, A., Reitebuch, O., Delville, P., Werner, C., Delaval, A., Boitel, C., Herrmann, H., Nagel, E., Romand, B. Streicher, J., Bénech, B., Bock, O., Caccia, J.L., Durand, P., and Guénard, V., Analysis of IOP2B land-sea breeze case during the ESOMPTE experiment. 10th Conference on Mountain Meteorology and MAP Meeting 2002, 17-21 June, Park City, UT, http://ams.confex.com/ams/10Mountain/10MntMet/index.html, 2002.

Bevis, M., Businger, S., Herring, T., Rocken, C., Anthes, R.A, and Ware, R.H., GPS Meteorology: remote sensing of the atmospheric water vapor using the Global Positioning System, $J$. Geophys. Res., 97, 15787-15801, 1992.

Bevis, M., Businger, S., Chiswel, S., Herring, T., Anthes, R., Rocken, C. and Ware, R., GPS meteorology: mapping zenith wet delays onto precipitable water, Journal of applied meteorology, 33, 379-386, 1994.

Bock, O., Tarniewicz, J., Thom, C., and Pelon, J., Effect of small-scale atmospheric inhomogeneity on positioning accuracy with GPS, Geophys. Res. Lett., 28, No. 11 , p. 2289, 2001.

Bock, O., Doerflinger, E., Masson, F., Walpersdorf, A., Van Baelen, J., Tarniewicz, J., Troller, M., Somieski, A., Geiger, A. and Bürki, B. GPS water vapor project associated to the ESCOMPTE programme: description and first results of the field experiment, Phys. Chem. Earth, 29, 149-157, 2004.

Braun, J., Rocken, C. and Ware, R., Validation of line-of-sight water vapor measurements with GPS, Radio Sci., 36, 459-472, 2001.

Braun, J., C. Rocken, and J. Liljegren, Comparisons of line-of-sight water vapor observations using the global positioning system and a pointing microwave radiometer, Journal of Atmospheric and Oceanic Technology, 20, 5, 606-612, 2003.

Brunner, F. K. and Gu, M., An improved model for the dual frequency ionosphéric correction of GPS observations, Manuscripta Geodaetica, 16, 205-214, 1991.

Businger, S., Chiswell, S.R., Bevis, M., Duan, J., Anthes, R.A, Rocken, C., Ware, R.H., Exner, M., VanHove, T., and Solheim, F., The promise of GPS in atmospheric monitoring, Bull. Amer. Meteor. Soc., 77, 5-18, 1996.

Chen, G., and Herring, T., Effects of atmospheric azimuthal asymmetry on the analysis of space geodetic data, Journal of geophysical research, 102, B9, 20489-20502, 1997.

Cros, B., Durand, P., Cachier, H., Drobinski, PH., Fréjafon, E., Kottmeier, C., Perros, P., Peuch, V., Ponche, J-L., Robin, D., Said, F., Toupance, G. and Wotham, H., The ESCOMPTE program: an overview, Atmospheric Research, in press, 2003. 
Davis, J.L., Herring, T., Shapiro, I., Rogers, A. and Elgered, G., Geodesy by radio interferometry: Effects of atmospheric modelling errors on estimation of baseline length, Radio. Sci., 20, 1593-1607, 1985.

Davis, J.L., Elgered, G., Niell, A.E. and Kuehn, C.E., Ground-based measurements of gradients in the wet radio refractive index of air, Radio Sci., 28, 1003-1018, 1993.

Delbarre, H., P. Augustin, P. Fréville, B. Campistron, F. Saïd, B. Benech, F. Lohou, V. Puygrenier, and E. Fréjafon, Ground-based remote sensing observation of the complex behaviour of the Marseille boundary layer during ESCOMPTE, Atm. Res., this issue.

Doerflinger, E., Bayer, R., Chery, J. and Bürki, B., The Global Positioning System in mountainous areas: Effect of the troposphere on the vertical accuracy, C.R. Acad. Sci.Paris, 326, 319325,1998

Duan, J., Bevis, M., Fang, P., Bock, Y., Chiswell, S., Businger, S., Rocken, C., Solheim, F., VanHove, T., Ware, R.H., McClusky, S., Herring, T.A., King, R.W., GPS meteorology: direct estimation of the absolute value of precipitable water, J. Appl. Meteorol., 35, 830-838, 1996.

Elgered, G., Tropospheric radio path delay from ground-based microwave radiometry, in Atmospheric Remote Sensing by Microwave Radiometry, edited by M.A. Janssen, pp. 215-258, John Wiley, 1993.

Elòsegui, P., and J. L. Davis, Accuracy Assessment of GPS Slant-Path determination, GPS Meteorology: Ground-Based and Space-Borne Applications, Workshop, International Workshop on GPS Meteorology, Tsukuba, http://dbx.cr.chiba-u.jp/Gps_Met/gpsmet/CD1_Proceedings_PDF/papers.html, 2003.

Fang P., Bevis, M., Bock, Y., Gutman, S. and Wolfe, D., GPS meteorology: Reducing systematic errors in geodetic estimates for zenith delay, Geophys. Res. Lett., 25, 3583-3586, 1998.

Flores, A., Ruffini, G. and Rius, A., 4D tropospheric tomography using GPS slant wet delays, Annales Geophysicae, 18, 223-234, 2000a.

Flores, A., Atmopsheric Tomography Using Satellite Radio Signals, PhD Thesis, http://www.tdx.cesca.es, 2000b.

Flores, A., Rius, A., Vilà, J. and Escudero, A., Spatio-Temporal Tomography of the Lower Troposhere Using GPS Signals, Phys. Chem. Earth, 26, A, 405-411, 2001 a.

Flores, A., J. Vilà, L. P. Gradinarsky, and A. Rius, Tomography of the Lower Troposphere Using a samll dense network of GPS receivers, IEEE Transactions on Geoscience and Remote Sensing, 39, 2, 439-447, 2001b.

Foelsche, U. and Kirchengast, G., Tropospheric water wapor imaging by combination of ground-based and spaceborne GNSS sounding data, J. Geophy. Res., 106, D21, 27221-27231, 2001.

Gradinarsky, L., Sensing atmospheric water vapor using radio waves, $P h D$ Thesis, Departement of Radio and Space Science, School of Electrical Engineering, Chalmers University of Technology, Göteborg, Sweden, 2002. 
Gradinarsky, L., Haas, R., Elgered, G. and Johansson, J. Wet path delay and delay gradients inferred from microwave radiometer, GPS and VLBI observations, Earth Planets Space, 52, 10, 695698, 2000.

Gradinarsky, L., Johansson, J., Bouma, H., Scherneck, H. and Elgered, G., Climate monitoring using GPS, Phys. Chem. Earth, 27, 335-340, 2002.

Gutman, S., S. R. Sahm, S. G. Benjamin, B. E. Schwartz, K. L. Holub, J. Q. Stewart, and T. L. Smith, Rapid Retrieval and Assimilation of Ground Based GPS Precipitable Water Observations at the NOAA Forecast Systems Laboratory: Impact on Weather Forecasts, Journal of the Meteorological Society of japan, 82, 1B, 351-360, 2004.

Jerret, D., and Nash, J., Potential uses of surface based GPS water vapour measurements for meteorological purposes, Phys. Chem. Earth, 26, A, 457-461, 2001.

King, R. and Bock, Y., Documentation for the GAMIT GPS Analysis Software, release 10.0, Departement of Earth, Atmospheric and Planetary Sciences Massachusetts Institute of TechnologyScripps Institution of Oceanography University of California at San Diego., 2000.

Niell, A., Global mapping functions for the atmosphere delay at radio wavelengths, Journal of Geophysical Research, 101, B2, 3227-3246, 1996.

Niell, A. E., A. J. Coster, F. S. Solheim, V. B. Mendes, P. C. Toor, R. B. Langley, C. A. Upham: Comparison of Measurements of Atmospheric Wet Delay by Radiosonde, Water Vapor Radiometer, GPS, and VLBI. J. Atmos. Oceanic Technol., 18, 830-850, 2001.

Rocken, C., VanHove, T., Johnson, J., Solheim, F., ware, R., Bevis, M., Chiswell, S.R. and Businger, S., GPS/STROM-GPS sensing of atmospheric water vapor for meteorology, J. Atmos. Oceanic Technol., 12, 468-478, 1995.

Rogers, C., Inverse methods for atmospheric soundings: theory and practice, 256pp., World Sci. Publ., Singapore, 2000.

Ruffini, G., Cardellach, E., Flores, A., Cucurull, L. and Rius, A., Ionospheric calibration of radar altimeters using GPS tomography, Geophysic research Letter, 25, 3771-3774, 1998.

Tregoning, P., Boers, R. and O'Brien, D., Accuracy of absolute precipitable water vapor estimates from GPS observations, Journal of Geophysical Research, 103, 28, 701-719, 1998.

Walpersdorf, A., Bock, O., Doerflinger, E., Masson, F., Van Baelen, J., Somieski A. and Burki, B., Data analysis of a dense GPS network operated during the ESCOMPTE campaign: First results, Phys. Chem. Earth, 29, 201-211, 2004.

Ware, R., Alber, C., Rocken, C. and Solheim, F., Sensing Integrated Water Vapor along GPS Ray Paths, Geophys. Res. Lett., 24, 417-420, 1997.

Ware, R., Fulker, D., Stein, S., Anderson, D., Avery, S., Clark, R., Droegemeier, K., Kuettner, J., Minster J. and Sorooshian, S., SuomiNet: A real-time National GPS Network for Atmospheric Research and Education, Bull. Am. Met. Soc., 81, No. 4, 2000. 
Yuan, L., Anthes, R., Ware, R., Rocken, C., Bronner, W., Bevis M. and Businger, S., Sensing Climate Change Using the Global Positioning System, J. Geophys. Res., 98, No. D8, 14925-14937, 1993. 


\section{Figures}

Figure 1: Schematic representation of the Slant Integrated Water Vapour (SIWV) in a heterogeneous atmosphere. The cone is the maximum angular aperture of the GPS antenna.

Figure 2: a - Schematic view in 2D of the discretisation of the space and the assumed straight rays between ground receivers and GPS satellites. $\mathrm{b}-\triangle \mathrm{SIWV}$ is the path-length of one ray in one cell in three dimensions.

Figure 3a-d: Eight horizontal slices from 250 to 3750 meters high through a synthetic model (squares) and the resulting inverted model (circles). Anomalies in the synthetic model $=1$. Values in the circles are the values of the retrieved field. See text for comments.

Figure 4: View of the dense GPS network extending over 20km x $20 \mathrm{~km}$ near Marseille.

Figure 5: Water vapour vertical profiles at the GPS station CINQ at 12, 14 and $16 \mathrm{H} \mathrm{UTC,} 26$ June 2001. Red line: initial model. Green line: inverted model. Black line: radio-sounding. Numbers on the green line are the diagonal terms of the resolution matrix. The horizontal error bars on the red line is the a priori model error.

Figure 6: Vertical cross-sections at 12, 13 and 14 H UTC, 26 June 2001. Top: North-South cross-section at the longitude of $5.39^{\circ}$. Bottom: East-West cross-section at the latitude of $43.31^{\circ}$. Cross-sections lines are indicated in the small inserted map. 


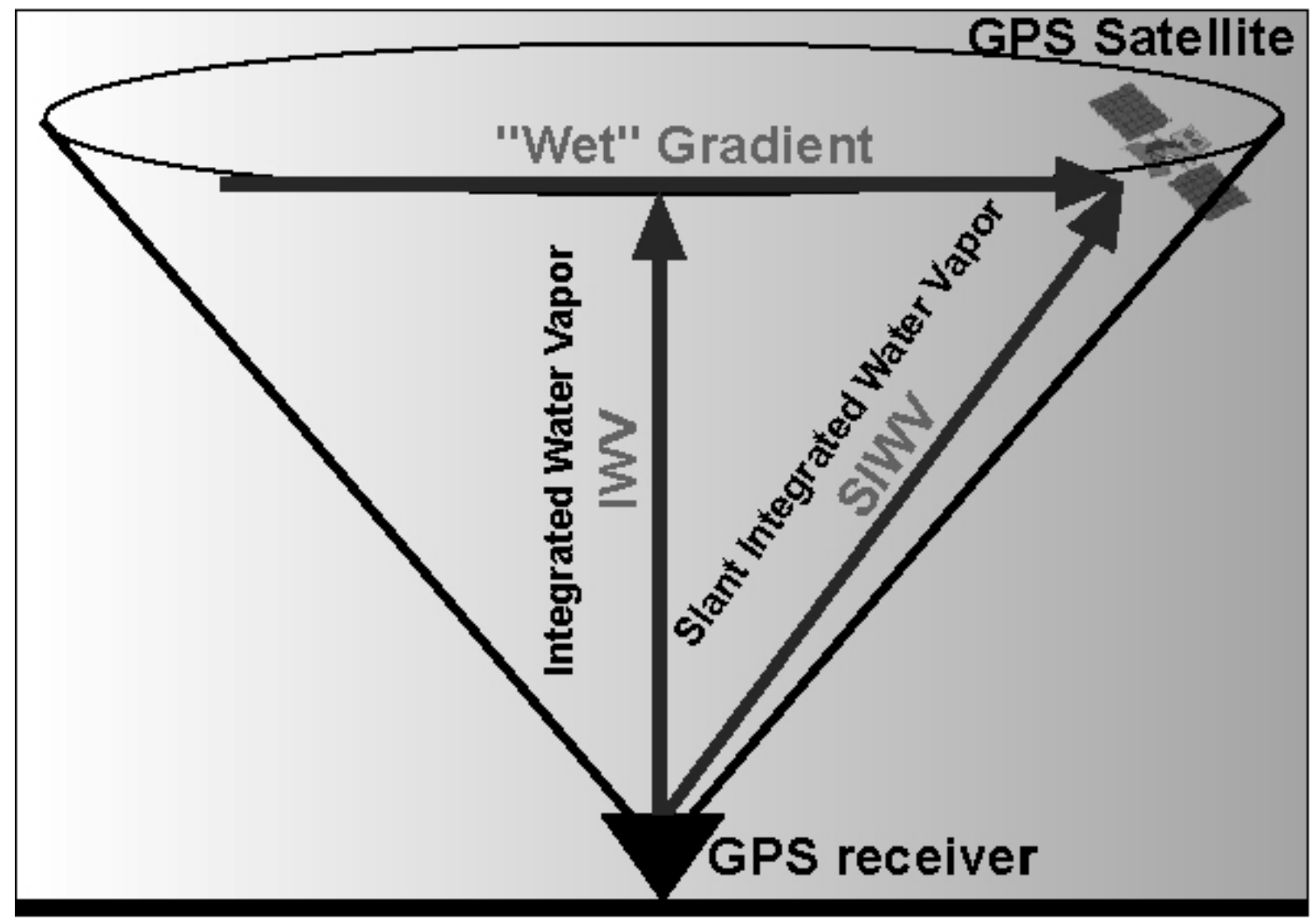

Fig. 1 

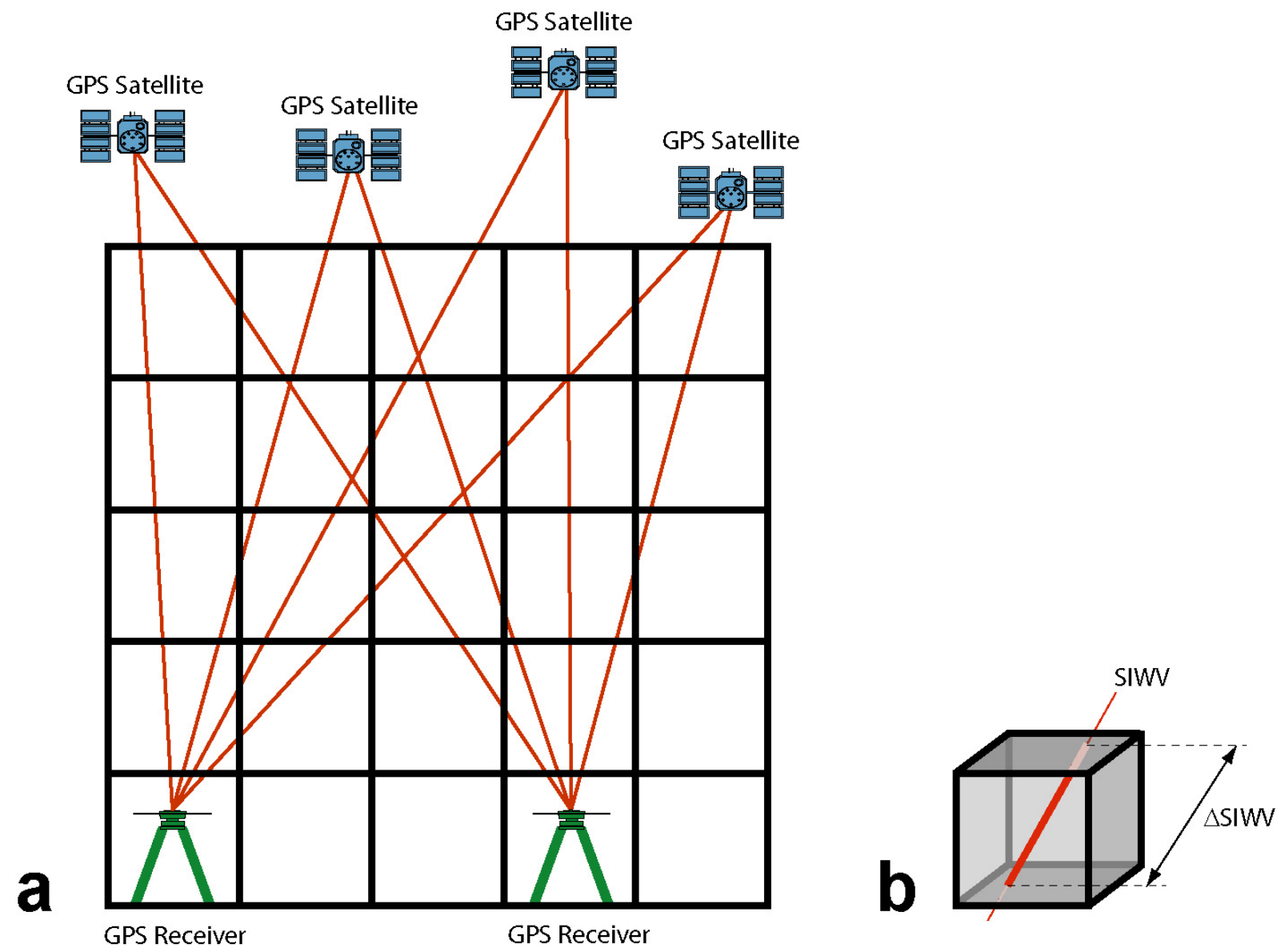

Champollion et al. figure 2 

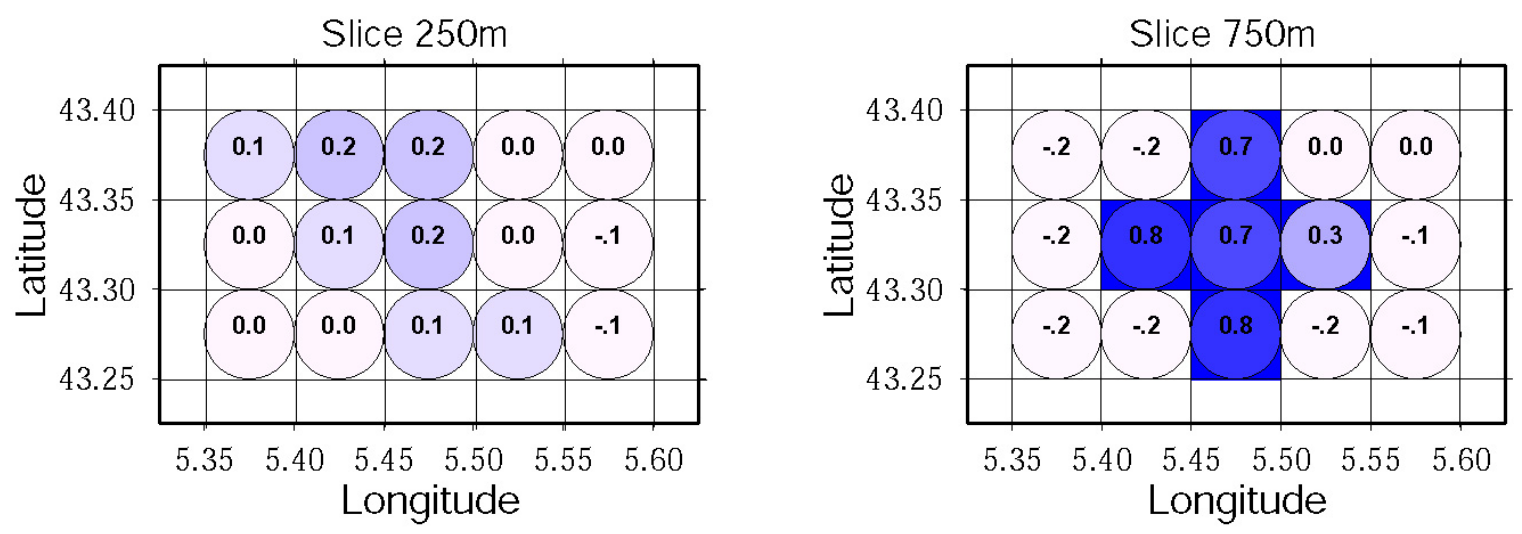

Slice $1250 \mathrm{~m}$

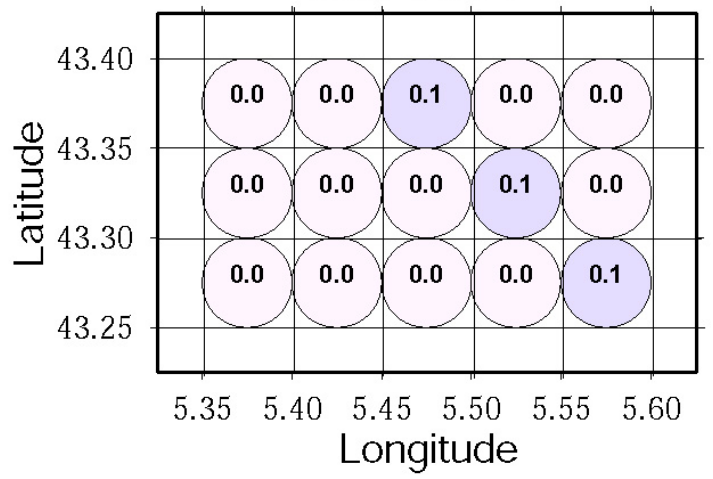

Slice $1750 \mathrm{~m}$

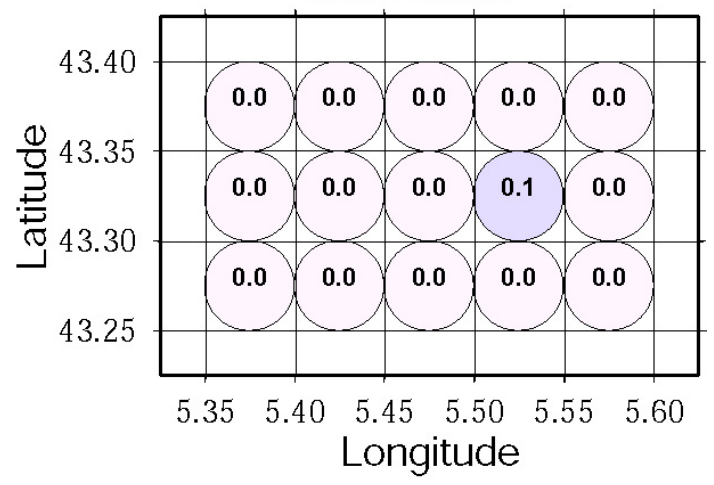

Slice $2250 \mathrm{~m}$

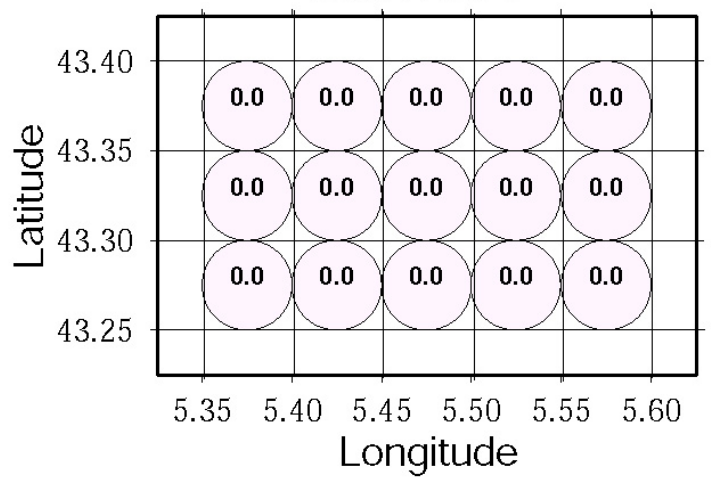

Slice $2750 \mathrm{~m}$

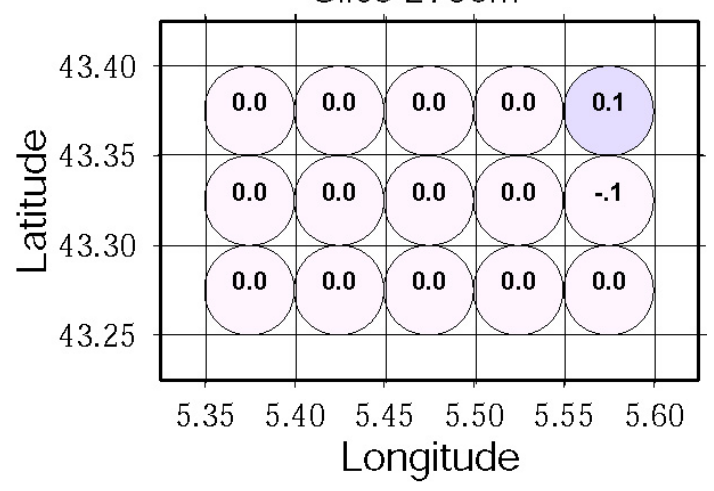

Slice $3250 \mathrm{~m}$

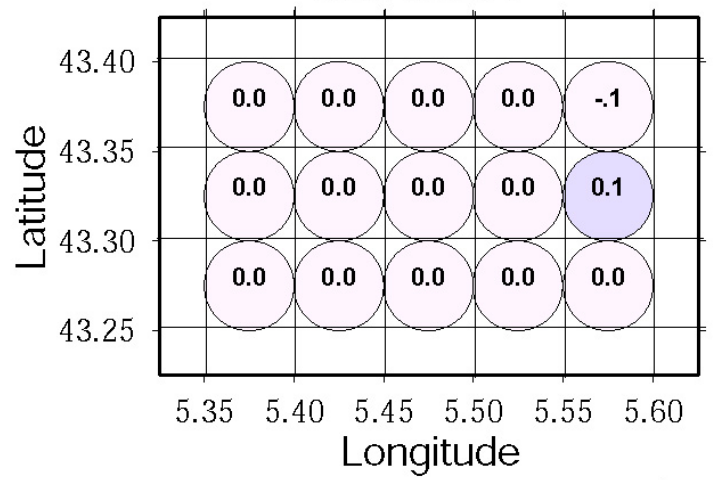

Slice $3750 \mathrm{~m}$

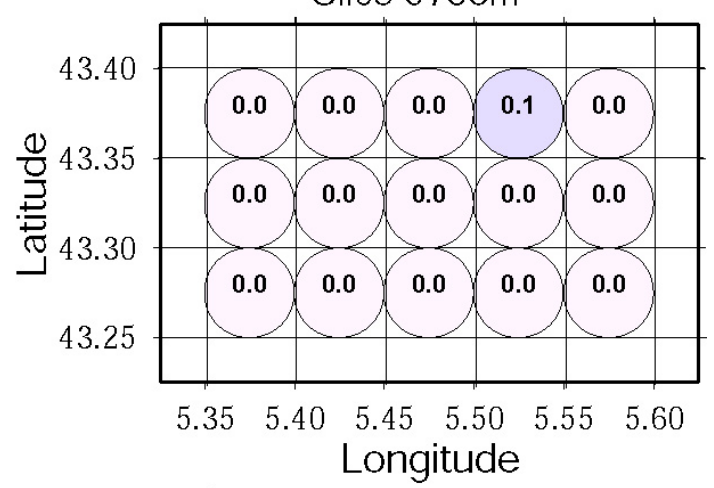

Figure 3a

Champollion et al. 

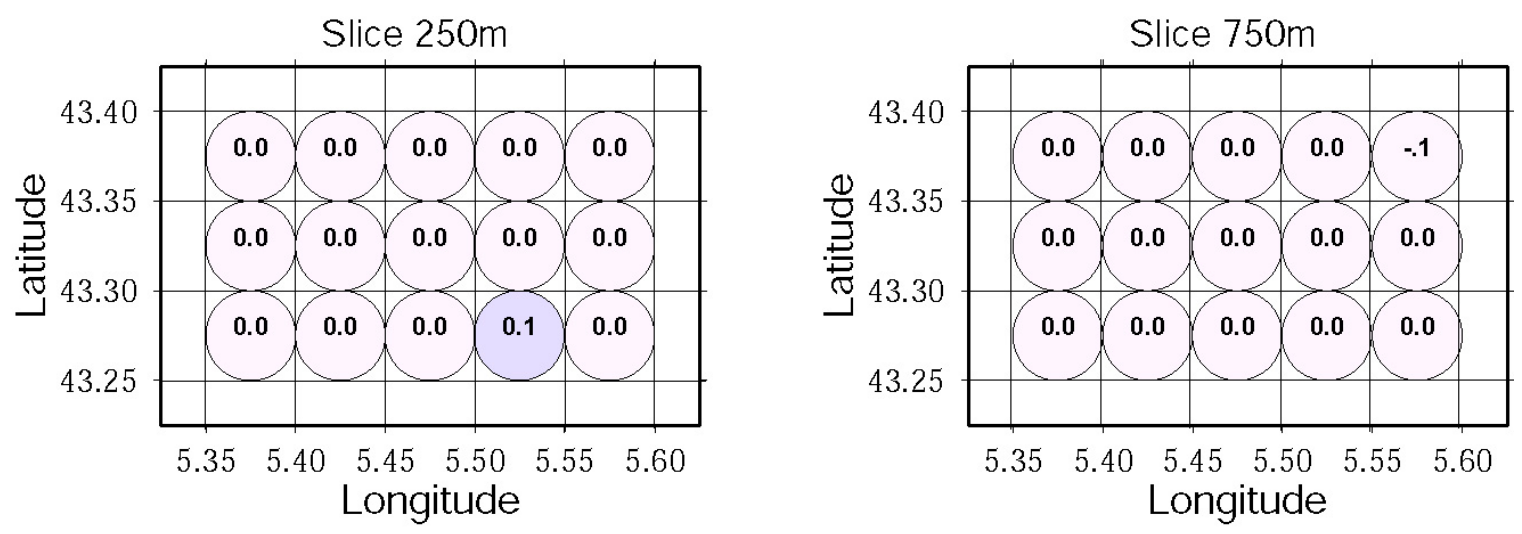

Slice $1250 \mathrm{~m}$

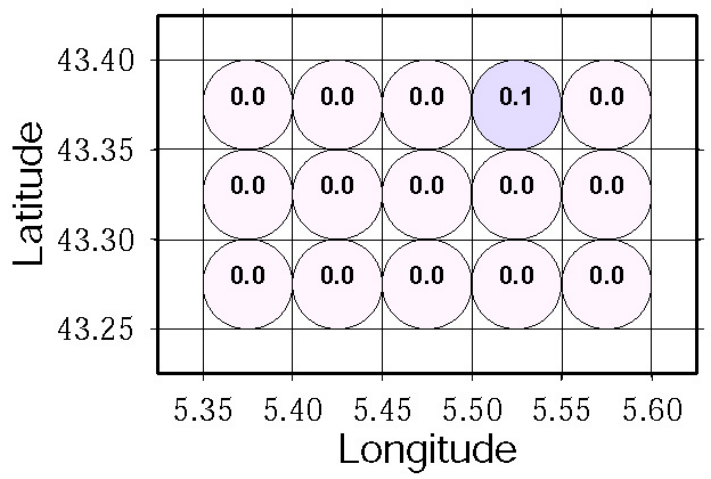

Slice $1750 \mathrm{~m}$

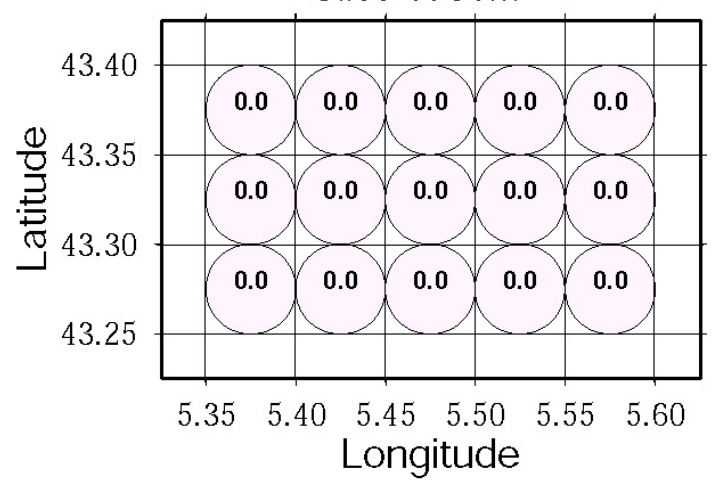

Slice $2250 \mathrm{~m}$

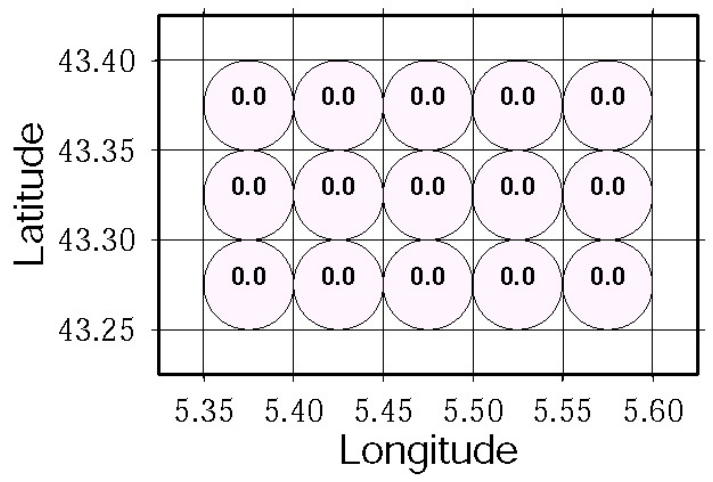

Slice $3250 \mathrm{~m}$
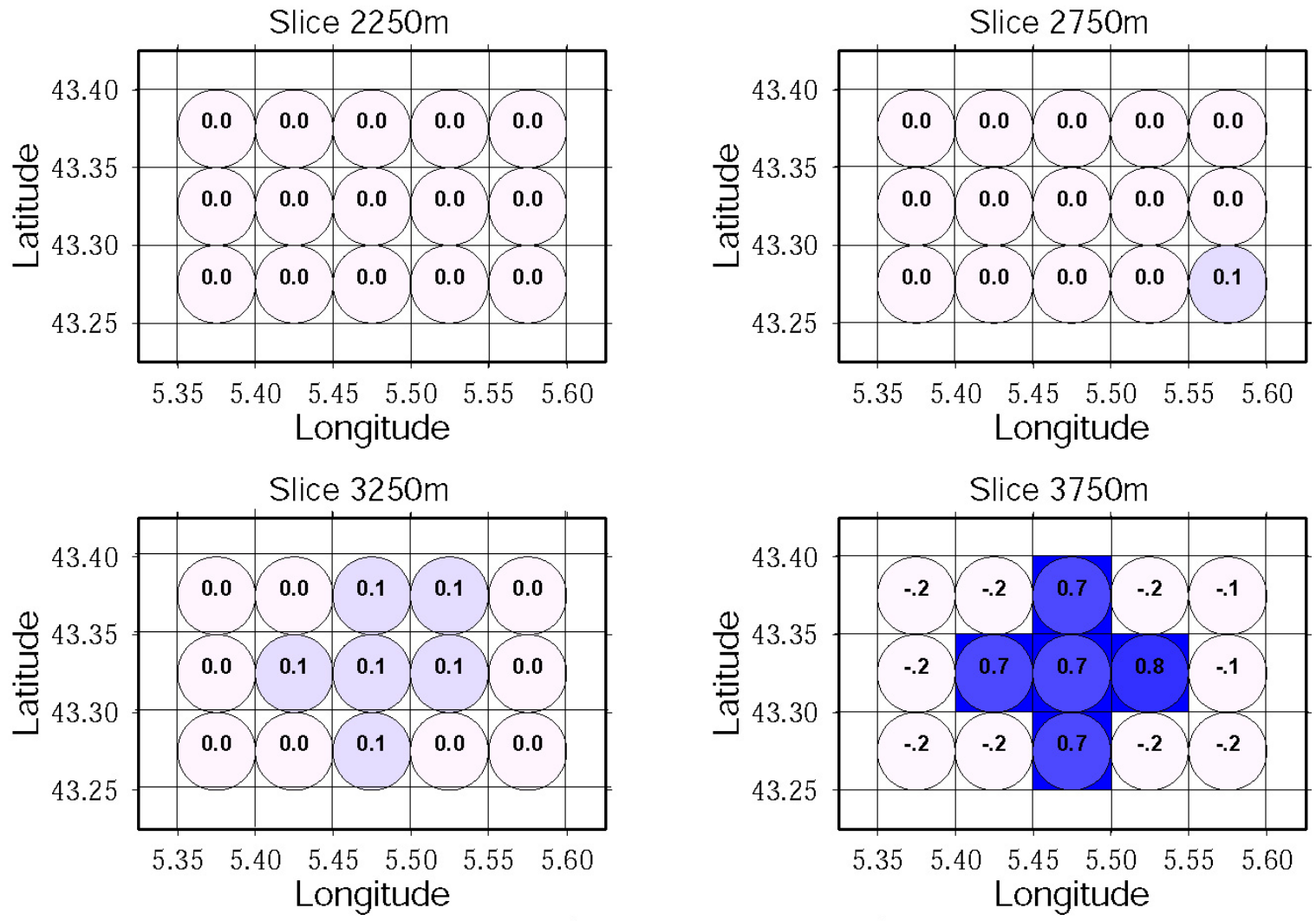

Slice $3750 \mathrm{~m}$

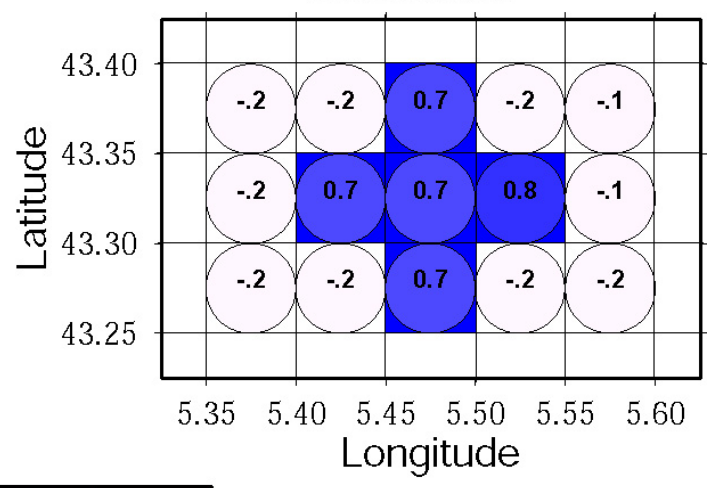

Figure $3 b$

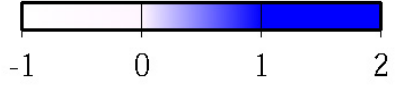

Champollion et al. 

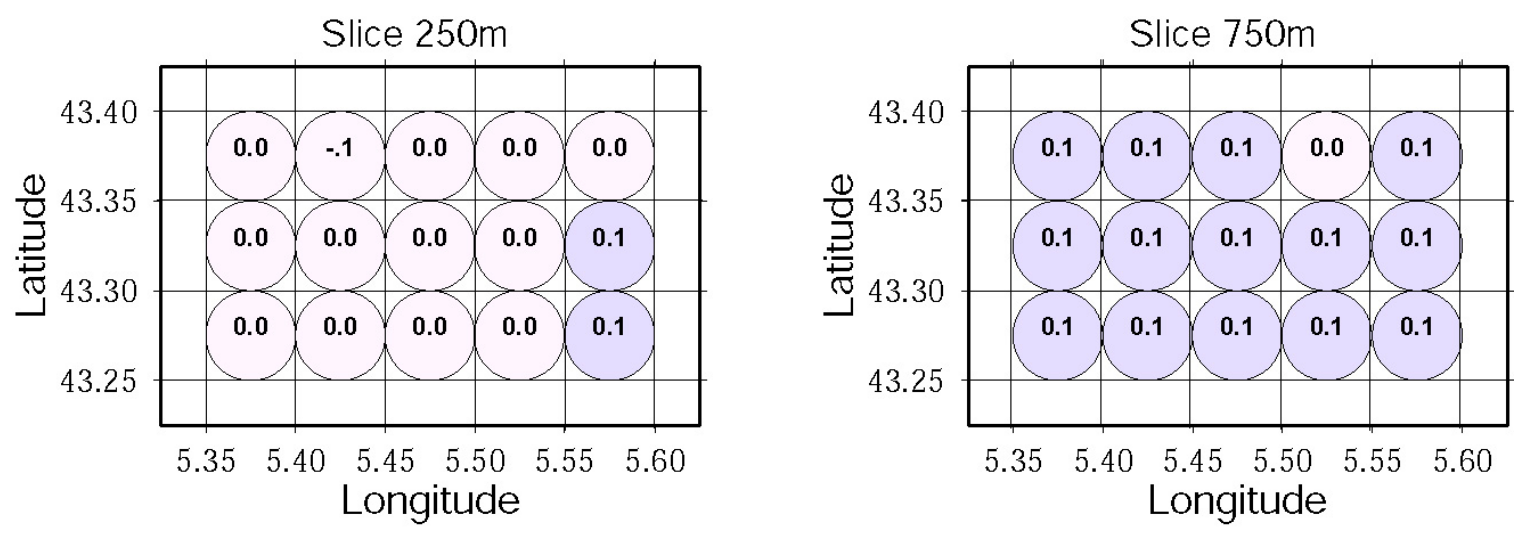

Slice $1250 \mathrm{~m}$

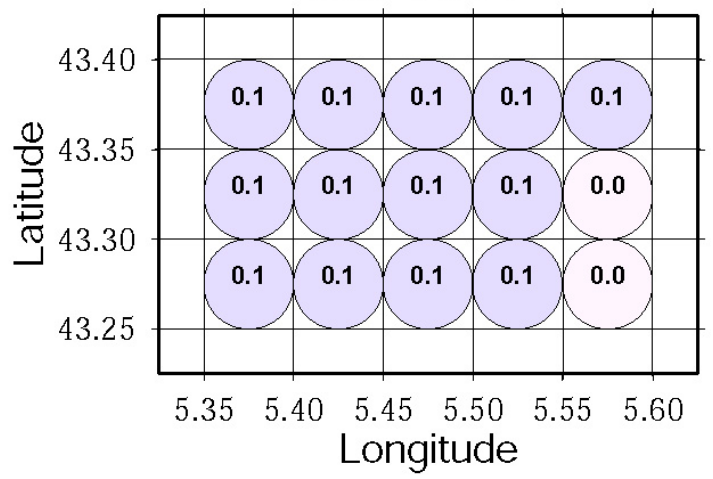

Slice $2250 \mathrm{~m}$

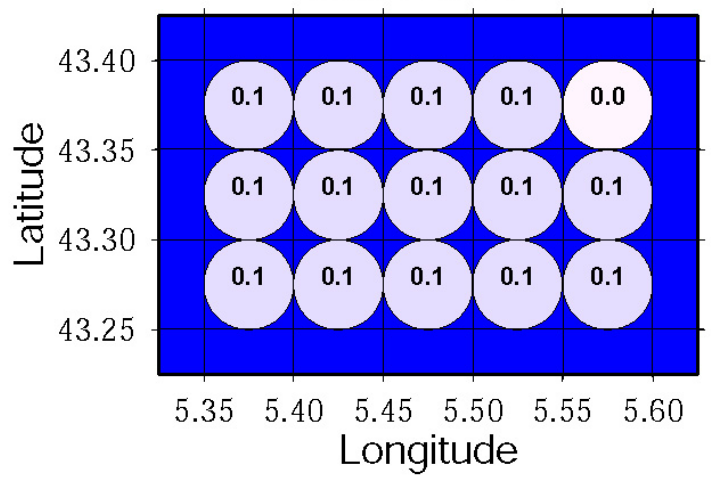

Slice $3250 \mathrm{~m}$

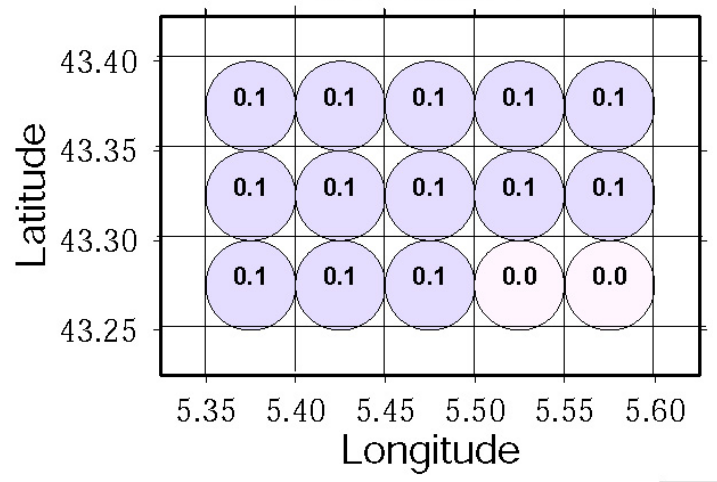

Slice $1750 \mathrm{~m}$

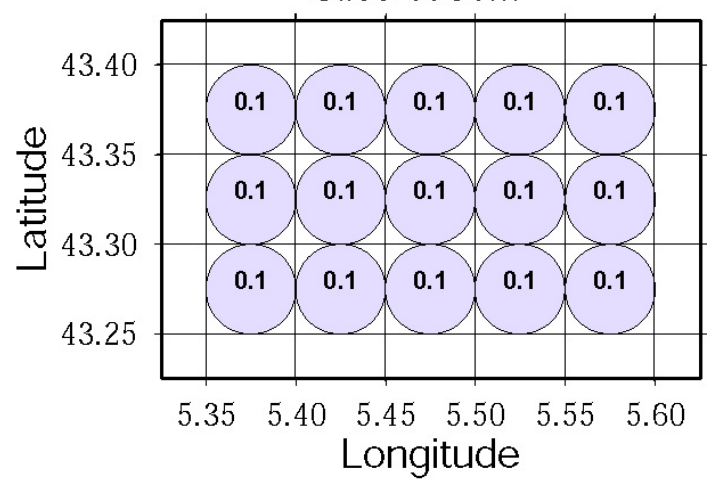

Slice $2750 \mathrm{~m}$

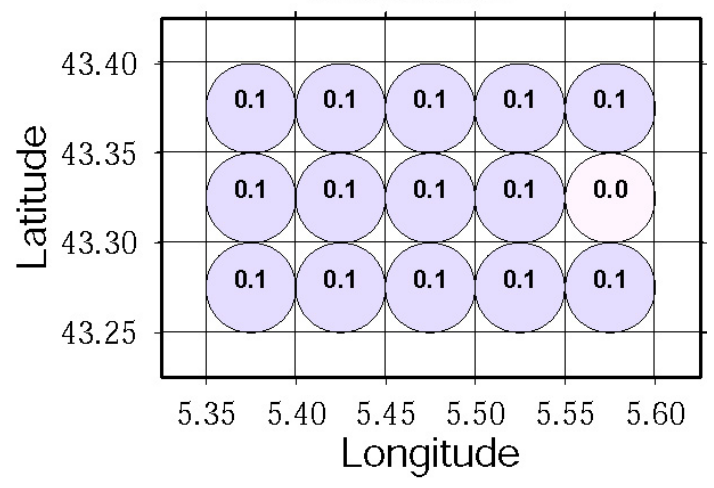

Slice $3750 \mathrm{~m}$

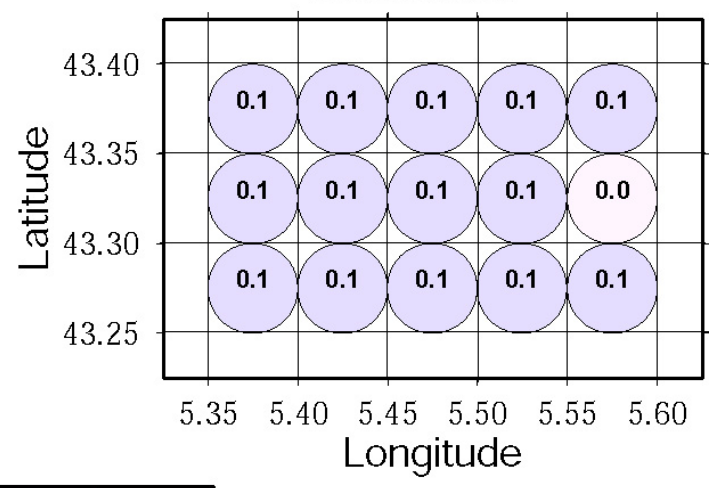

Figure 3c

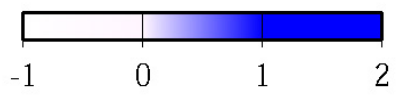

Champollion et al. 

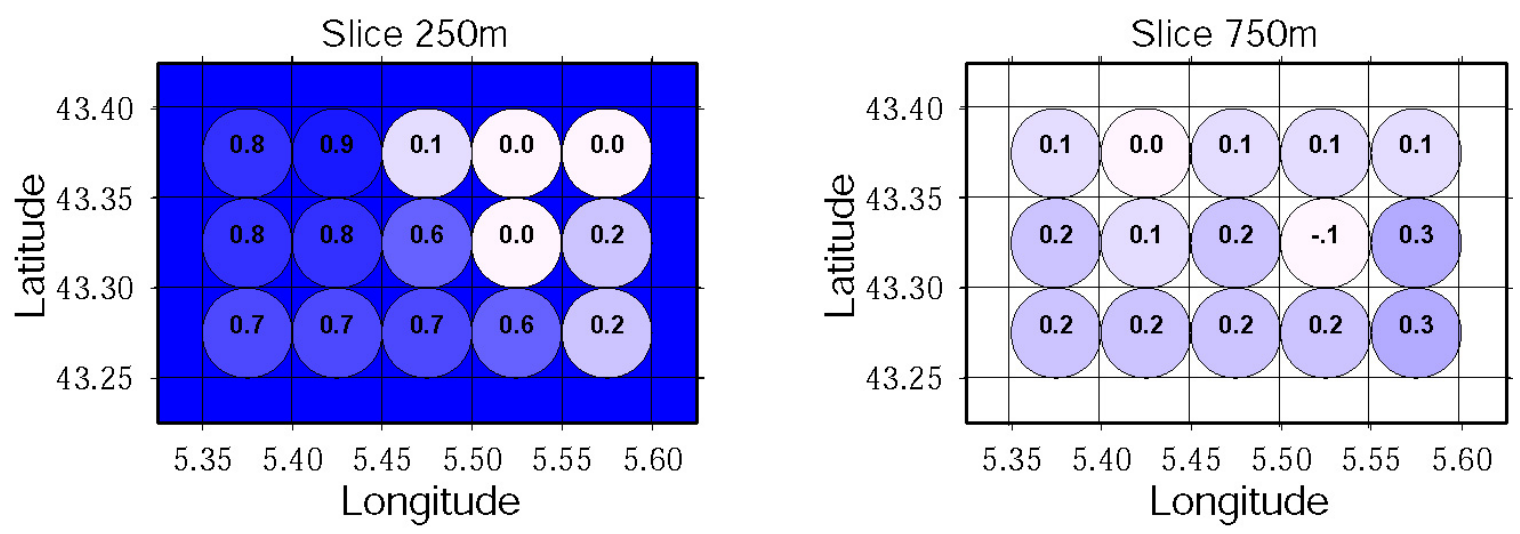

Slice $1250 \mathrm{~m}$

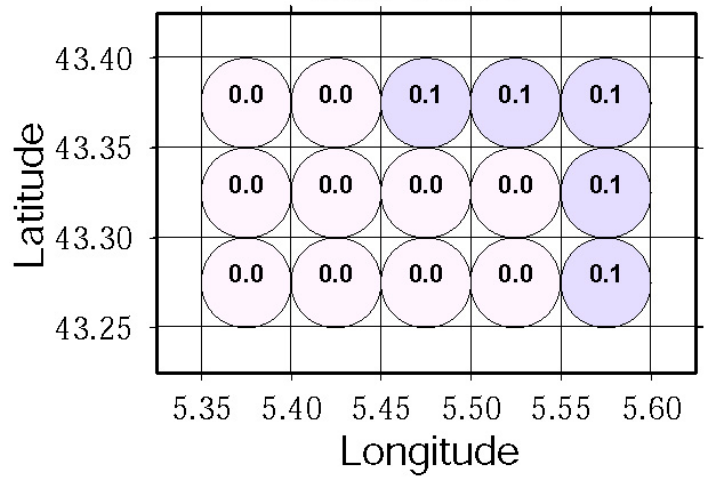

Slice $1750 \mathrm{~m}$
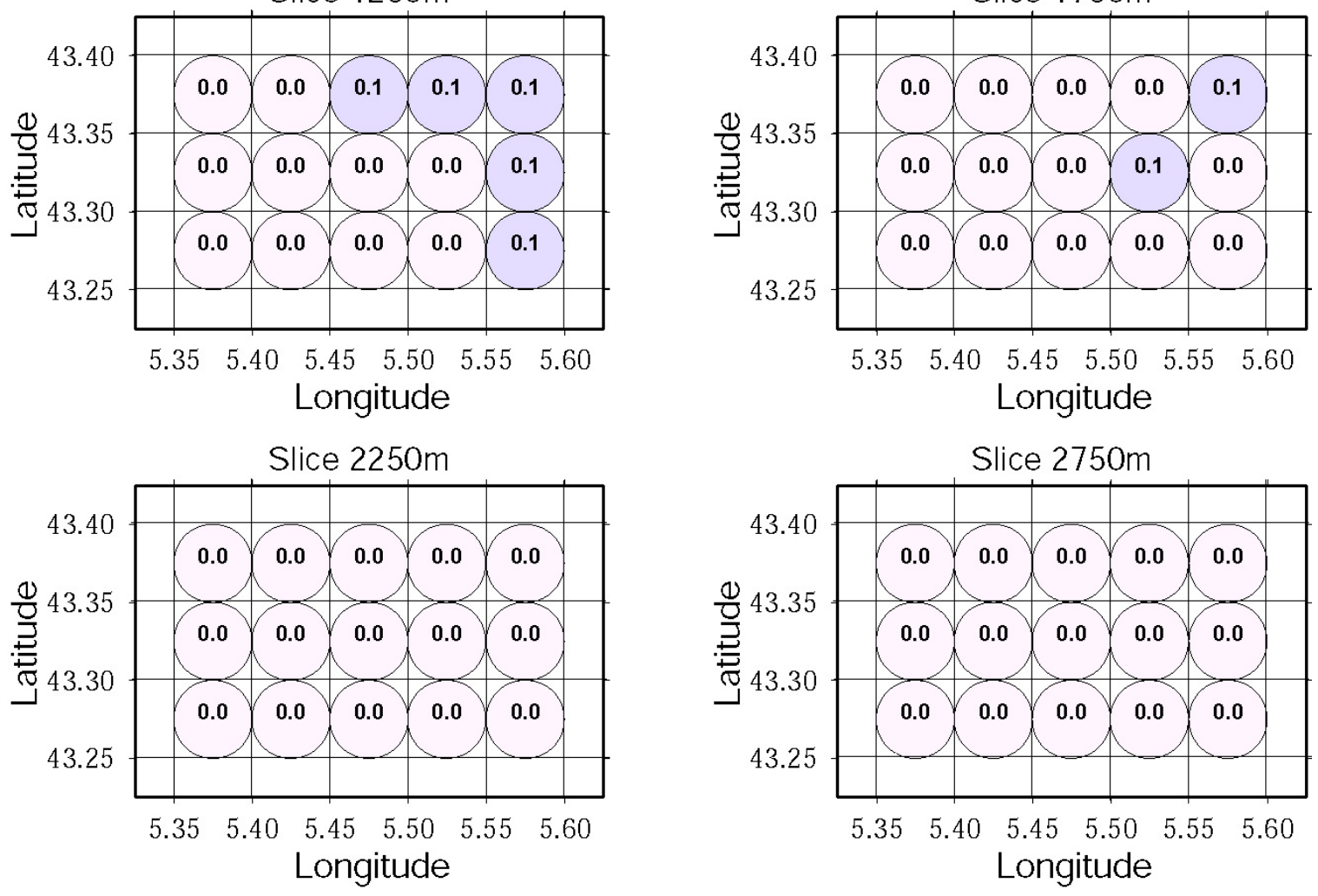

Slice $3250 \mathrm{~m}$
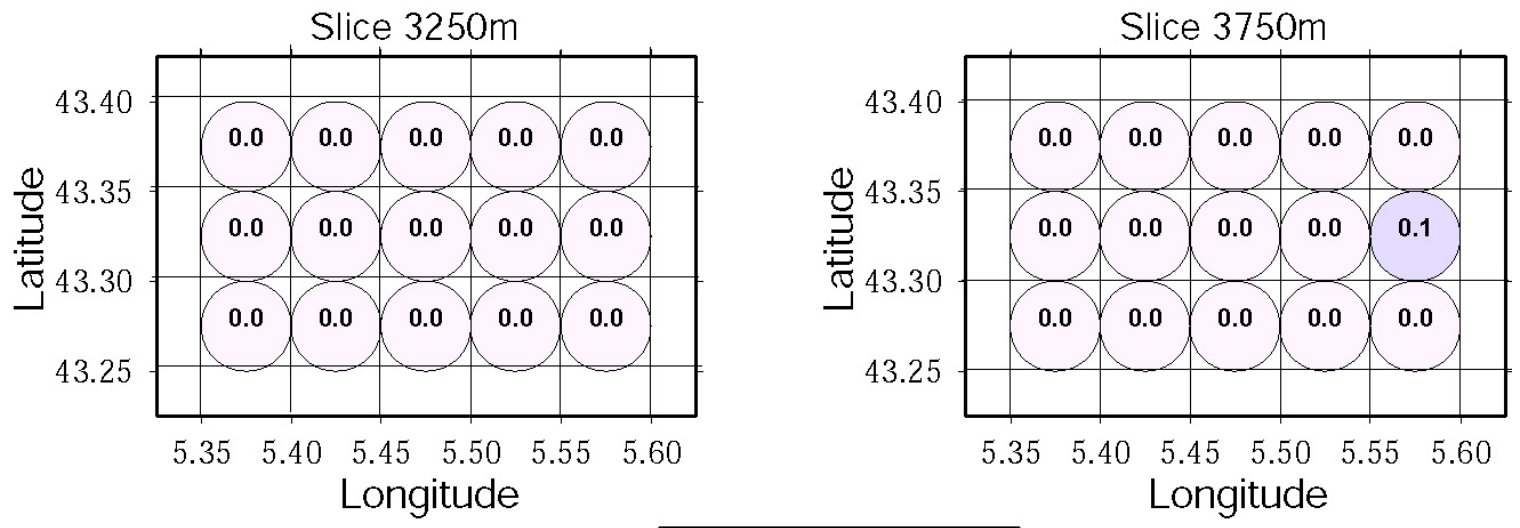

Figure 3d

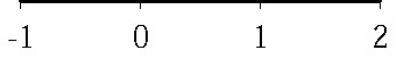

Champollion et al. 


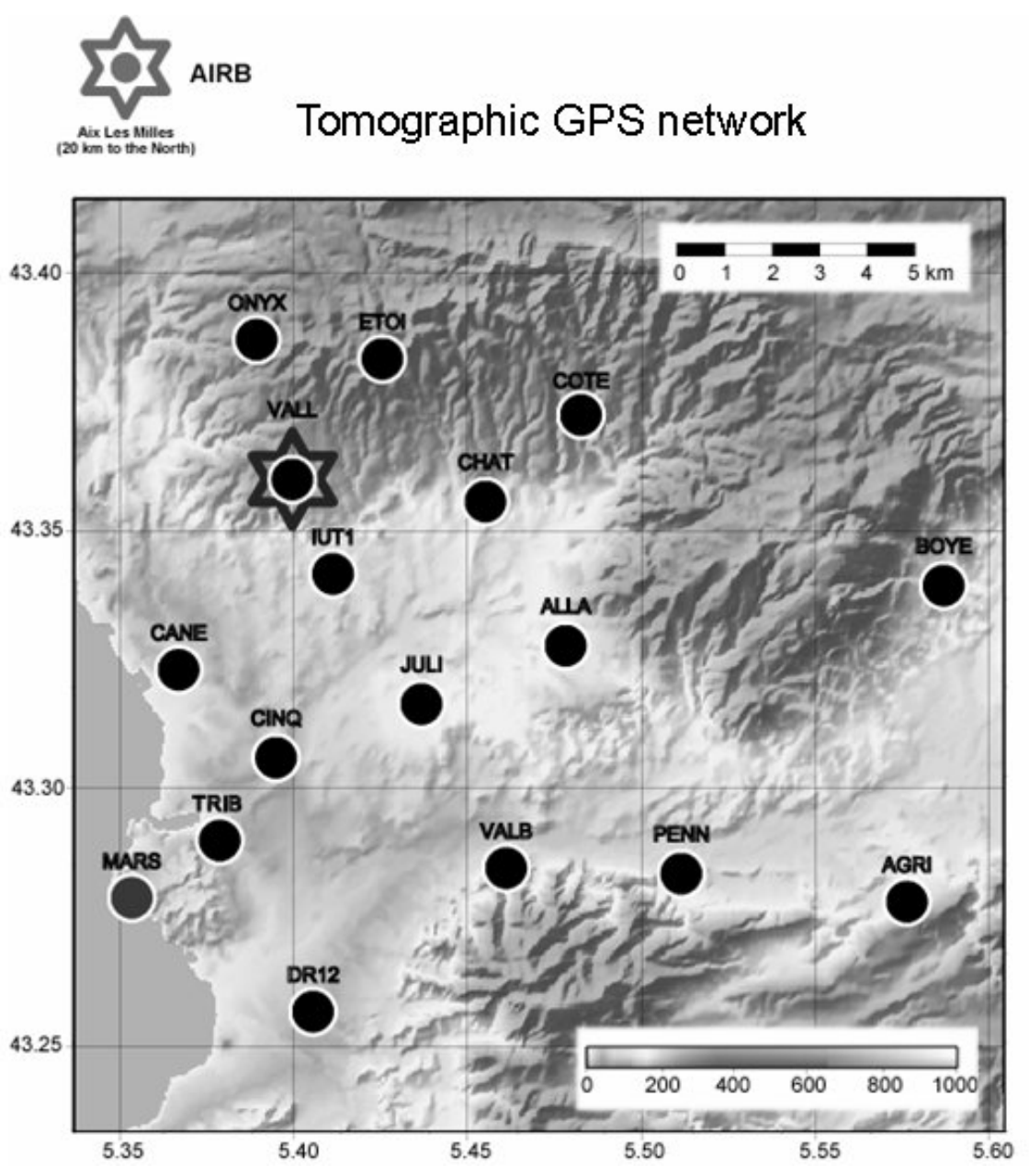

Fig. 4 


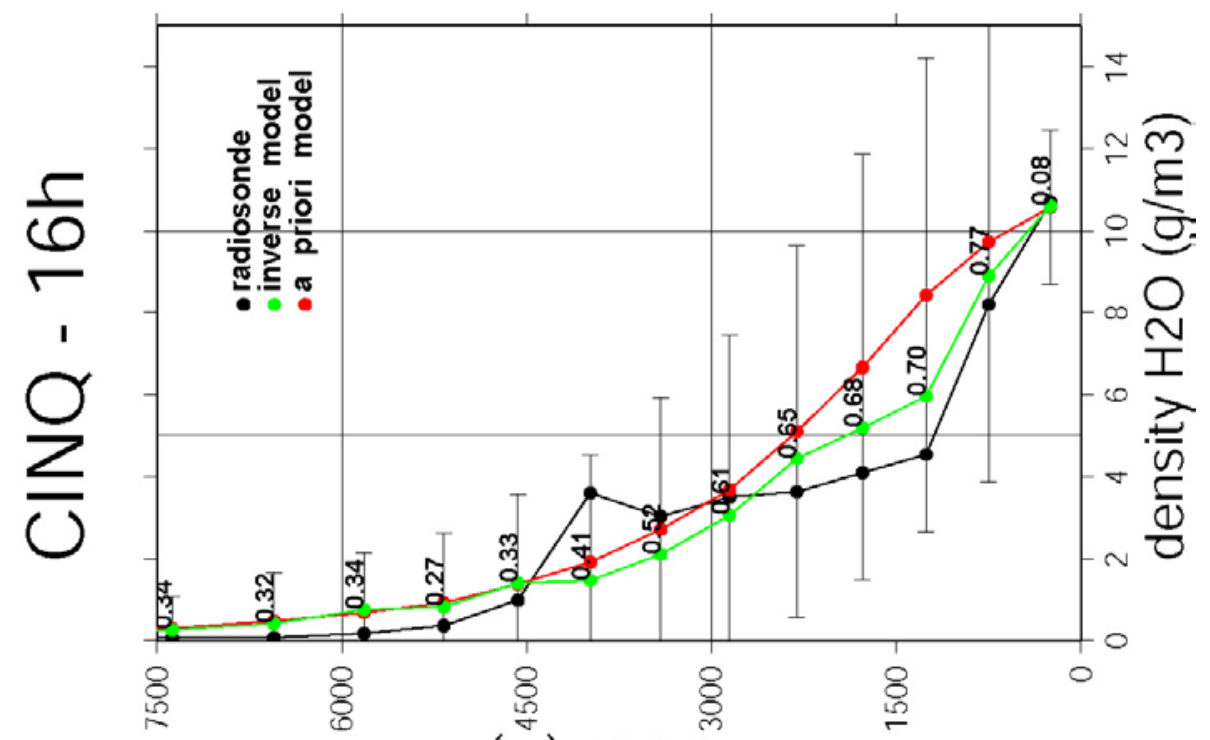

(ii) әрп!!!|

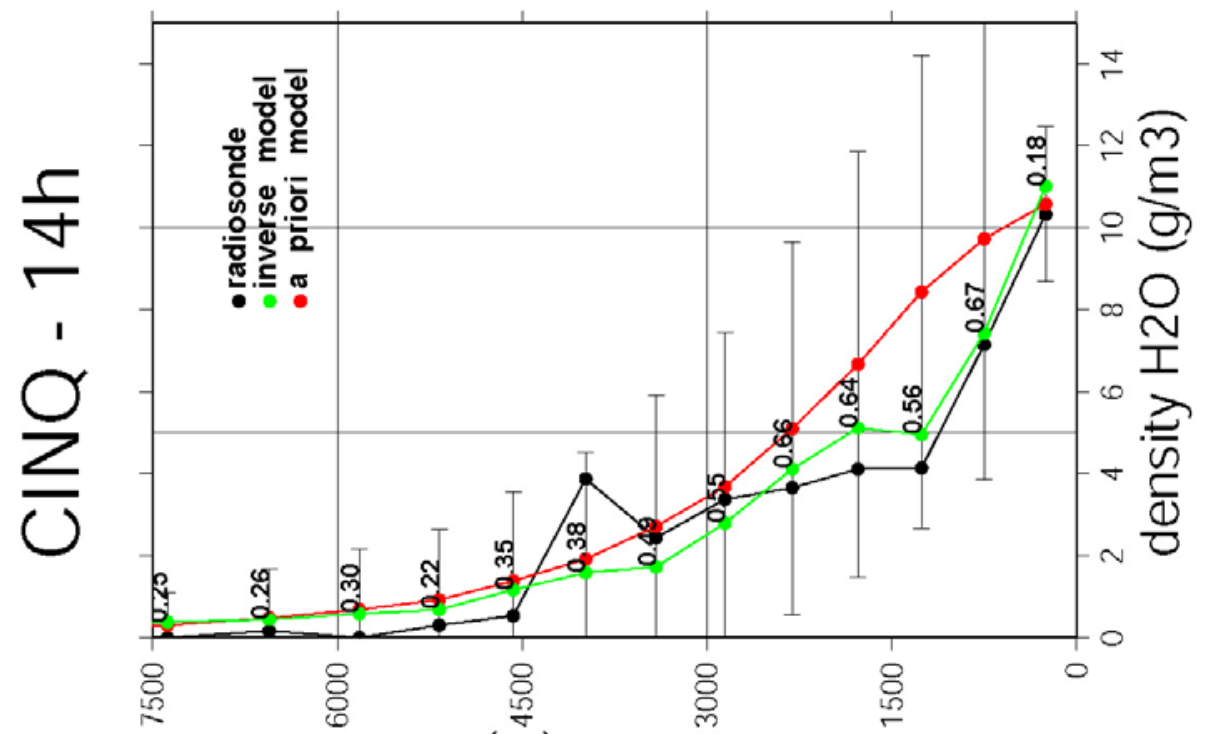

(i) әрm!!ı|

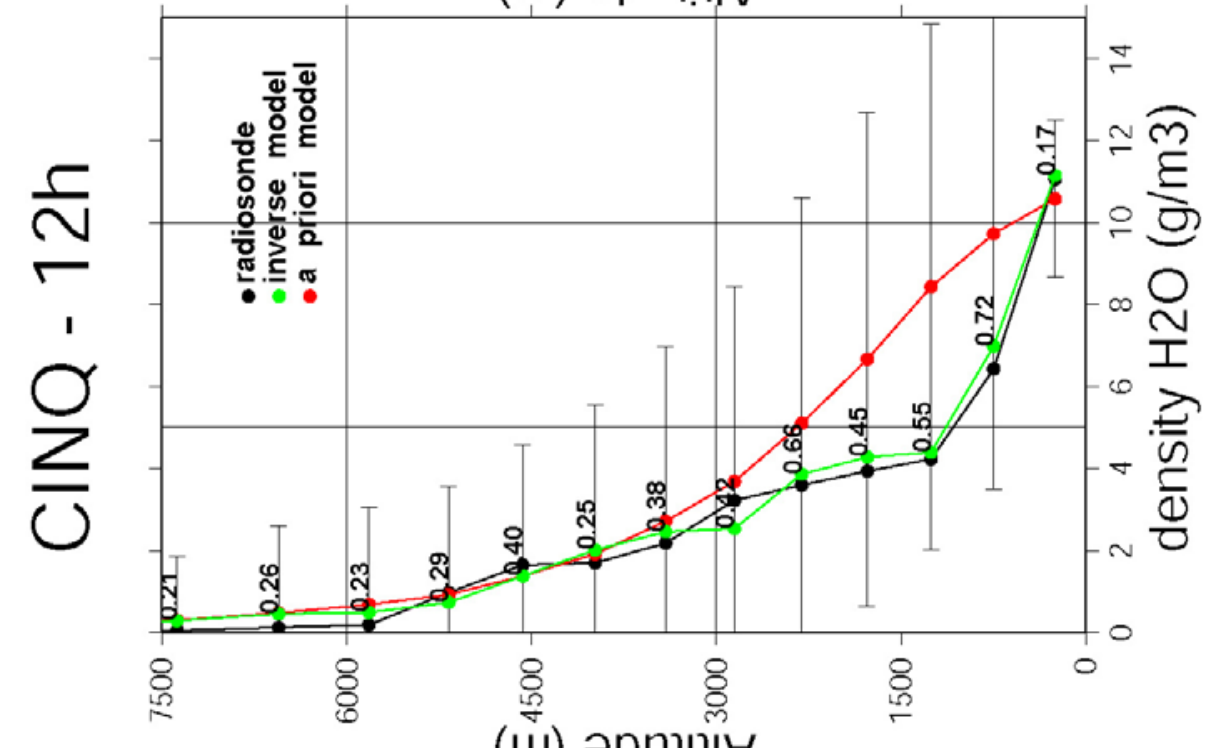

(w) әрпฺ!ฺ|

Fig. 5 

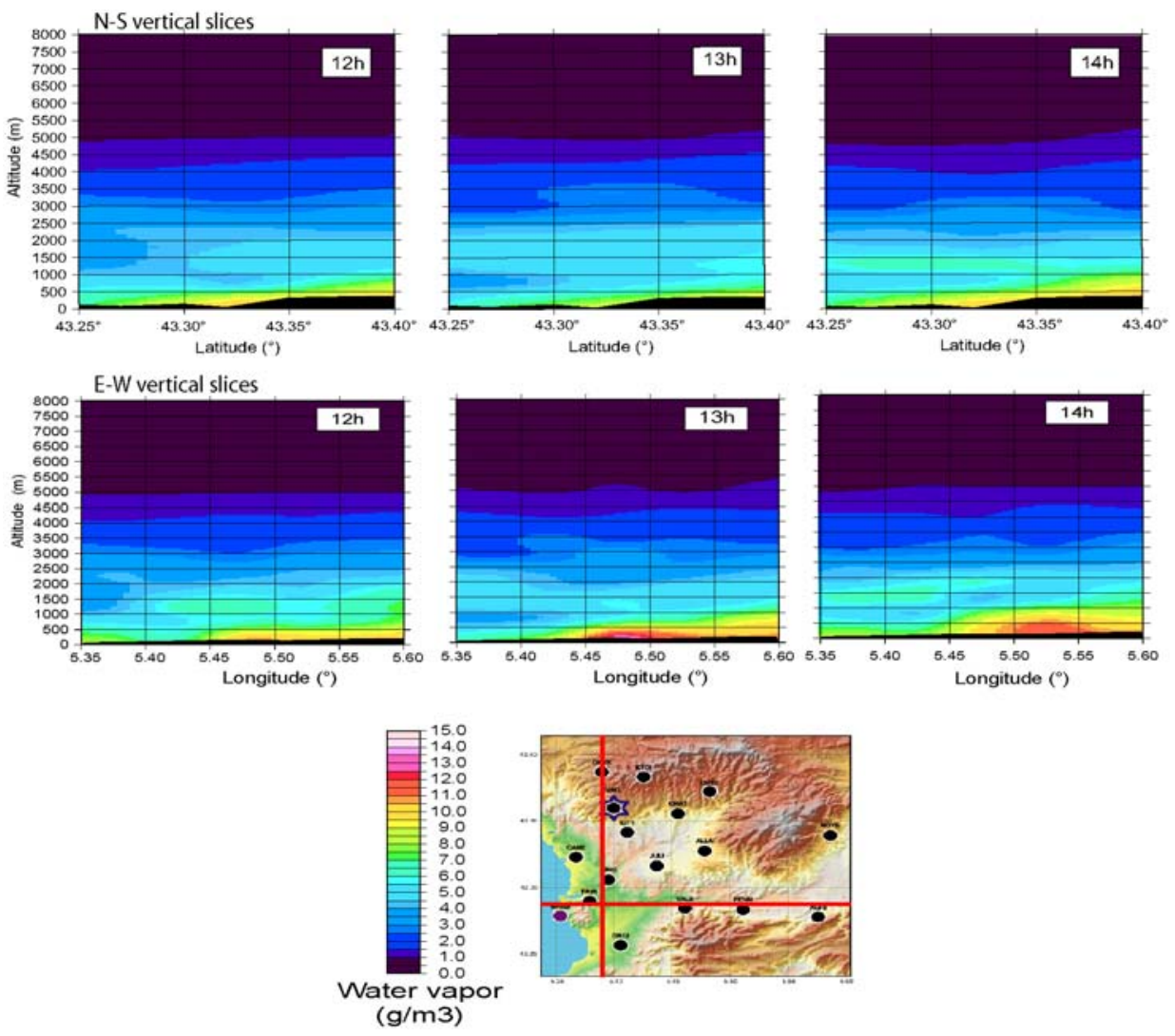

Fig. 6 